\title{
Conversational Forms of Instruction and Message Layer Design
}

Andrew S. Gibbons III

Brigham Young University, andy_gibbons@byu.edu

Elizabeth Boling

Indiana University

Follow this and additional works at: https://scholarsarchive.byu.edu/facpub

Part of the Instructional Media Design Commons

\section{BYU ScholarsArchive Citation}

Gibbons, Andrew S. III and Boling, Elizabeth, "Conversational Forms of Instruction and Message Layer Design" (2018). Faculty Publications. 2523.

https://scholarsarchive.byu.edu/facpub/2523

This Conference Paper is brought to you for free and open access by BYU ScholarsArchive. It has been accepted for inclusion in Faculty Publications by an authorized administrator of BYU ScholarsArchive. For more information, please contact ellen_amatangelo@byu.edu. 


\title{
Conversational Forms of Instruction and Message Layer Design
}

\author{
Andrew S. Gibbons \\ Brigham Young University \\ Elizabeth Boling \\ Indiana University \\ Preface
}

This monograph reports research into the validity of an architectural theory of instructional design by examining in detail the theoretical and historical basis for one of the seven functional "layers" that the theory postulates. The architectural theory describes how these functions can be designed independently by invoking designer skill and knowledge specialties related to specific layers of the design. In this view, strategy functions are designed by specialists in instructional strategy, while control, representation, and media execution logic (program) functions are designed by specialists in those areas. This monograph aligns design structure design team organization, and existing bodies of theory for the design of instructional messaging systems.

We review theoretical and historical literature from instructional design, instructional theory, conversation theory, the learning sciences, intelligent tutoring systems, and educational psychology. Within this literature, we are able to demonstrate the existence of the message as a structural abstraction, a design construct, and a practical building block for instructional designers. As we trace the development of the message construct historically, we are able to show that it has remained remarkably stable over time, independent of changing psychological, educational, and technological fashions, and we assert that the message construct provides a missing key to designing conversational forms of instruction. 
An overview of the terms and main concepts of the architectural theory is provided in Chapter 1, Instruction as a Conversation: The Imperative for Message Layer Design, to provide context for the detailed descriptions of the message layer in later chapters. The chapter argues that instruction takes place in the form of a conversation and asserts that approaching instructional design in terms of an architectural theory can lead more readily to designs that are conversational.

Two of the functional layers of an architectural design are keys to achieving conversational designs - the message layer and the control layer. The message layer defines the system of message elements that the instructional source uses to communicate to the learner the substance of its directions, didactics, coaching, and scaffolding. The control layer describes the means by which learners express their responses, choices, and actions, completing the conversational cycle.

Chapter 1 gradually narrows its focus to the message layer, building a case for the existence of the layer as a practical thought tool for designers. It refers the reader to research on other layers proposed within the architectural theory.

Chapter 2, Conversation Theory and the Message Construct, reviews a theory of conversation analysis (CA) that supplies structural terms and principles for the discussion of conversation moves. The chapter shows how basic elements of instructional message structure correspond with structures provided by $\mathrm{CA}$ theory that permit the integration of conversation 
structures with strategic instructional structures. This chapter underscores the difference between analytic theories of conversation analysis that explain what is happening within conversations and synthetic theories that can be used to provide structure for the design of instructional conversations.

\section{Chapter 3, Message Structure, Educational Psychology, and Instructional Technology,} examines historical cases in which the message construct played a central role in structuring highly interactive and conversational instruction. It begins with an account of Markle's "grammar" of programmed instruction frame design. Markle described in detail the message elements from which her program frames were assembled. Secondly, this chapter recounts how an early computer-based design project, the TICCIT project, devised a plan for matching dynamic computer display content with instructional strategies. Finally, the chapter describes how the analysis of classroom conversations relates to a systematic way for guiding conversations. Our account shows how these three early examples identified the existence of a construct for the management of message structures for the purpose of designing conversational instructional forms.

Chapter 4, Message Structure and Intelligent Tutoring Systems, describes how increasingly adaptive instructional designs depended on devising more competent systems of message analysis. In this chapter we show that the foregrounding of the strategic and mechanical concerns of designs overshadowed interest in formalisms for conversation structure. This chapter also describes a broader concept of message as an abstract, pre-representational structure for capturing communicative intent, including hard-to-express and nuanced meanings, including 
feelings and emotion, which have impact on the clarity and efficiency of instructional communication.

\section{Chapter 5, Message Structure, the Learning Sciences, and Social Learning Theory,} continues the theme of broadening the concept of message to show how the message construct and its natural expression in everyday classroom instructional settings can be used by classroom instructors as well as instructional designers as a practical design tool. The emphasis on the social dimensions of instructional design led to the deliberate factoring of conversational structures as a controlled variable capable of expressing instructional strategic as well as social concerns. Three socially-motivated instructional theories - CSILE, problem-based learning, and reciprocal teaching — are evaluated in terms of their intentional management of the message structure.

Chapter 6, Conclusion, summarizes the main findings of this research, which are that the message construct bridges a historical gap between basic structures of instructional strategy and basic structures of conversational interaction at a fundamental level. This finding validates the message construct theoretically and practically and in doing so lends additional support to the architectural theory of instructional design.

This monograph completes a long-term project for defining and giving substance to the major design layers described in an architectural theory of instructional design. A comprehensive expression of the theory is given in Gibbons (2014). Additional publications argue the validity of 
four of the design layers described by the theory: the content layer (Gibbons, Nelson \& Richards, 1999a; Gibbons Nelson, \& Richards, 1999b; Gibbons, 2000; Gibbons, 2001; Gibbons 2014; Helps, 2007), the strategy layer (Gibbons, 2020), the message layer (this work), and the control layer (Gibbons \& Langton, 2016). Three layers that provide essential services to these main layers remain to be explored in depth. The four layers that have been validated to this point comprise the theoretical backbone of the architectural theory and of individual designs.

Further work to establish the theory would entail documenting analytic case studies: (a) showing the successful proactive application of the theory, and (b) retrospective analyses of existing successful designs to identify elements that correspond with the claims of the theory. Helps (2007) provides an example of the former type of study, by demonstrating the stability of content layer constructs amid the turbulent churning of technical content in university-level information technology training and the difficulties of keeping course syllabi updated. The case studies reviewed in this monograph and the validation studies previously performed for the other three main layers exemplify the latter type of study, seeking to identify stable layer-specific constructs through reverse engineering of theoretical literature.

\section{References}

Gibbons A. S., Nelson, J. S. \& Richards, R. E. (2000). The nature and origin of instructional objects. In D. Wiley (Ed.), The instructional use of learning objects. Bloomington, IN: Association for Educational Communications and Technology, 25-58. 
Gibbons, A. S. (2001). Model-centered instruction. Journal of structural learning and intelligent systems, 14(4), 511-540.

Gibbons, A. S., Nelson, J. S. \& Richards, R. E. (1999a). Theoretical and practical requirements for a system of pre-design analysis. White paper prepared for the Human-Systems Simulation Center of the Idaho National Engineering and Environmental Laboratory, Idaho Falls, ID. https://scholarsarchive.byu.edu/facpub/1330

Gibbons, A. S., Nelson, J. S. \& Richards, R. E. (1999b). Model-centered analysis process (MCAP): A pre-design analysis methodology. White paper prepared for the Idaho National Engineering and Environmental Laboratory, Idaho Falls, ID. https://scholarsarchive.byu.edu/facpub/1328.

Gibbons, A. S. (2014). An architectural approach to instructional design. New York: Routledge.

Gibbons, A.S. \& Langton, M. B. (2016). The application of layer theory to design: The control layer. Journal of computing in higher education, 28, 97-135. http://scholarsarchive.byu.edu/facpub/2968

Gibbons, A. S. (2020). What is instructional strategy? Seeking hidden dimensions. Educational technology, research and development. Published online: 3 September 2020. Available at: https://rdcu.be/b6Ldw. https://doi.org/10.1007/s11423-020-09820-2. 
Helps, R. (2007). Dancing on quicksand gracefully: Instructional design for rapidly evolving technology courses. SIGITE '07: Proceedings of the $8^{\text {th }}$ ACM SIGITE conference on information technology education, 1-8. https://doi.org/10.1145/1324302.1324304. 


\section{Chapter 1 \\ Instruction as a Conversation: \\ The Imperative for Message Layer Design}

\subsection{Introduction and overview}

The architectural theory of instructional design (Gibbons \& Rogers, 2009; Gibbons, 2014) identifies seven major functions carried out by instruction, coinciding with seven independently designable "layers" of a design. The message layer is one of these. The purpose of this monograph is to establish the validity and utility of the message layer as an important functional unit of an instructional design. Doing so would represent a major step forward in our understanding of instructional design theory and practice.

Layering in designs is an emergent property of designs in many fields in response to increasing technological complexity (Baldwin \& Clark, 2000; Brooks, 2010). The layering of designs along the lines of artifact functions emerges naturally as a by-product of this complexity. In the early stages of a developing technology, relatively simplistic designs allow individual designers to "engineer" the entirety of their designs themselves, and the expression of their designs can be embodied in relatively simple descriptions. As the expectations of artifact performance escalate, however, the knowledge required to produce increasingly sophisticated products moves beyond the resources and knowledge of a single individual, and specialists join design teams that grow in more or less direct proportion with the knowledge needed to deal with the complexity of the artifact's expected functions.

Design specialists on a team normally speak their own community-specific languages and employ design tools and methods that are different from those of other team members 
(Rheinfrank \& Evenson, 1996; Bucciarelli, 1994). These are employed because specialized knowledge and skill bases allow them to create more sophisticated and impactful designs and to do so more efficiently than those who do not speak their language. The history of instructional design and technology follows this unfolding pattern exactly, especially in the design of technology-based instructional artifacts. Designers who once could program computer-based artifacts at the keyboard using simplified authoring languages designed several functions by themselves. They created program code, designed visual effects, framed the subject-matter, wrote instructional messages, devised responding and interaction patterns, framed broad instructional strategies, and designed data collection and storage routines. Given today's more complicated technologies, much higher product expectations, more complex and varied tools, and more elaborated design concepts, it would be almost impossible today to find anyone who could accomplish a professional quality design single-handedly.

Today, instructional design projects of commercial grade are routinely carried out by teams of design and development specialists that include instructional designers, writers, artists, programmers, internet specialists, editors, evaluators, and managers. For a web-based project, the task of programming alone has grown so complex that it requires multiple sub-sets of specialist skills to access resources from data bases, manage interactions adaptively, display resources tailored to the individual user, collect and analyze input from the user's controls, record responding patterns, and create user profiles for use in adapting future interaction plans. In addition, this list may include conditioning the product to work over the internet, playing it on a wide variety of user platforms, interacting seamlessly with multiple pre-packaged software 
routines (off-the-shelf programs and APIs), interfacing with cloud services, and optimizing response times by tuning and trimming the overall software design.

The modularization of design structure and the layering of designs is practiced in many design fields ${ }^{1}$. Modular designs are all about you: in your home, on your transportation, at work, and where you recreate. If you are reading this on a computer, you are using a highly modularized tool. The architectural theory of instructional design introduces this concept, called modular design, into the instructional design field. The theory suggests that instructional designers might with profit consciously implement a mode of layered thinking already implicit in the structure of their design teams but not widely recognized. This would not only to distribute design responsibility to the best-trained person but provide a foundation for further study of the design process itself, within individual layers. This monograph supports the claims of the architectural theory by examining in detail the unique theoretical and practical basis of one of the functional layers of an instructional design, the message layer.

This work on the message layer parallels earlier work validating other design layers: the content layer (Gibbons et al, 1999a; Gibbons et al, 1999b; Gibbons et al, 2000; Gibbons, 2001; Gibbons 2014; Helps, 2007), the strategy layer (Gibbons, 2020), and the control layer (Gibbons \& Langton, 2016). The control layer and the message layer share a special relationship: the function of the control layer is to carry communications from the learner to the learning source, the function of the message layer is to convey communications back from the learning source to the

\footnotetext{
${ }^{1}$ For example, computer and software design, tool and equipment design, architectural design and structural engineering, business and organizational design, automotive and aircraft design, and others. See, for example, Goldstein \& Bobrow, 1980; Brand, 1994; Fowler \& Beck, 1999; Baldwin \& Clark, 2000; Simmonds \& Ing, 2000.
} 
learner. Together, the message and control layers create the two-way channel of communication between the learner and the source of learning that is essential to the design of conversational instructional forms. The message and control layers are always implicit in instructional designs, because these functions are essential for instruction to even take place, but prior to this they have not received direct attention in their own right as related theoretical and practical design topics. Our project is to introduce the message layer for general consideration and lay out the evidence that it is a valid design concern that promises the advancement of practice generally in the field of instructional technology.

\subsection{Instruction as a conversation: Assumptions}

The following assumptions frame this research:

- Instruction is a conversational process engaged in by the mutual consent of two or more agents for the purposes of promoting learning for one or both of the agents and reducing information and performance disparities (Heritage, 2013; Gibbons, 2014, p.112).

- The conversational nature of instruction is inherent in interactions and the conversationality assumption applies to all forms of instruction, ranging from the most interactive to the most lecture-like, and including self-instruction. Changing conceptions of learning as a process of co-construction of knowledge, experiments with conversational tutoring systems, and the emergence of social learning theories have established that learning is a social and necessarily interactive, and therefore conversational process, including the internal processes attendant to self-directed learning. By viewing instruction as a conversational process, designers and teachers are encouraged to explore the deliberate implementation of more conversational and adaptive 
designs.

- Instructional conversation may entail the negotiation of instructional goals, roles, time frames, instructional methods, locations, interaction rules, and/or topics at some level of detail. Ideally, all participants have a voice in these negotiations (Fox, 1993).

\subsection{What constitutes a conversation?}

The concept of conversation is not amenable to exact definition. When human agents come into contact, they engage in interactions. This pattern of interaction is rooted in the earliest stages of childhood. Siegel (1999) explains that, "the mind emerges from the activity of the brain, whose structure and function are directly shaped by interpersonal experience" (p.1). He describes this in comprehensive terms:

The structure and function of the developing brain are determined by how experiences, especially within interpersonal relationships, shape the genetically programmed maturation of the nervous system. (p.2)

Infantile experiences program us to engage in conversation (Rogoff, 1990; Vygotsky, 1978). This means that conversation is more than a convenient social tool; it is the means by which we develop mentally through initially non-verbal interactions that result in attachment to others.

At the level of the mind, attachment establishes an interpersonal relationship that helps the immature brain use the mature functions of the parent's brain to organize its own processes. (Siegel, 1999, p. 67) 
Seigel describes the importance of "co-regulating contingent communication" that makes possible "the attunement of states of mind" (p. 70). It is hard to identify a form of communication that can be considered non-conversation given this understanding. Even a silent refusal to acknowledge the presence of another human can be interpreted as a strategic conversational move.

Conversation in all of its forms encompasses the full range of human interactions. Defining conversation more narrowly risks ignoring the aspects of desire, purpose, emotion, expressiveness, trust, and spontaneity that make conversations dynamic, unpredictable, and human. Much of our life's daily activity consists of conversations. It is not possible to draw a bright line to mark some as instructional and some not. For the purposes of this monograph, virtually all forms of human interaction are considered to be forms of instructional conversation, because no interaction with another leaves us or the other unchanged.

The challenge of the instructional designer is not to engage in rhetorical exercises to determine how to exclude certain interactions from being considered conversations, but to analyze, through research and development, which properties of conversations have the ability to bring about beneficial, intentional change and how to embody on those properties into designs.

The structures of everyday conversations provide affordances for the design of instructional conversations: the invitation, the acceptance, the engagement, the diagnostic, the utterance, the interpretation, the response, the trust, the fulfillment of intentions, and the termination. Unlike 
the broad range of everyday conversations, though, the designers of instructional conversations must warrant that their designs have certain properties:

- That they are harmless and safe, physically and emotionally

- That they consider both short-term impacts and long-term ones

- That they afford participants the maximum possible participation

- That they respect the participant's right to withdraw

If this definition of instruction and its most basic manifestation as conversation seems to overreach, it could be argued that our conceptions of learning interactions have been limited by traditional definitions of instruction that under-reach. The very idea that instruction is a conversation goes far beyond the traditional practice of categorizing types and patterns of instruction and expecting instructional instances to fit within one or another category. The term conversation also places the popular design concept of "interaction" into a new, much more profound perspective. Conceptions of conversation go far beyond the surface-click version of interaction and require qualities of thoughtfulness, intention, and deep processing be respected. The broader definition of instruction proposed here invites the designer to imagine endless new forms of conversational interaction that include new ways for soliciting willing, purposeful, and sustained engagement in learning conversations.

\subsection{Forms and dimensions of instructional conversation}

An incomplete but suggestive range of both new and traditional instructional forms is presented in Table 1. We consider them all to represent legitimate but very diverse forms of instructional conversation. Each may be expressed in a variety of specific configurations, suggesting that 
varieties of instructional conversation resist strict classification, rather inviting close examination

of structural properties that may reveal underlying principles of instructional conversationality.

Table 1. Some traditional and innovative forms of instruction that employ conversation in some way.

Direct lecture classroom instruction Non-adaptive computer-assisted instruction Live tutoring - peer and expert Automated tutoring Informal learning environments Reciprocal teaching environments Constructionist learning environments Communities of practice MOOCs

Distance educational forms

Web-based and e-learning forms

Online assessment systems

Playful environments
Learning companion systems Blended learning Computer-based management systems Technical simulations

Virtual reality systems Pedagogical agent systems Self-administered instructional packages Personal learning environments Programmed learning products Cooperative learning environments Problem solving environments Intentional learning environments Educational games 
Conversations in this incomplete list of forms exhibit variations along several dimensions that are common to any conversation (after Gibbons, 2014):

- $\quad$ Placement and sharing of initiative

- $\quad$ Self-perceived roles of participants

- $\quad$ Specific purposes/goals of participants

- $\quad$ Number of participants

- $\quad$ Location of participants

- $\quad$ Time between turns

- $\quad$ Length of turns

- $\quad$ Temporal contiguity of turns

- Duration of the conversation

- Shared standards of evidence and argumentation

- $\quad$ Degree of civility or mutual regard

- $\quad$ Presence of a mediator

- $\quad$ Number of shared symbolic, analogic, and metaphorical meanings

- Medium of communication

- Modes of expression

- $\quad$ Degree of willingness to participate

- $\quad$ Evident motives for participation

- $\quad$ Ulterior motives for participation

- $\quad$ Specific topic of conversation

- $\quad$ Respect for turn-taking 


\section{- Negotiability of conversation rules}

Conversations vary along a dimension of planned-ness. At one end of a continuum are structured conversations whose paths are anticipated and prepared for in advance. At the other end of the continuum are conversations that are spontaneous, context-derived, serendipitous, and opportunistic. Levinson (2013) describes a process by which the recipient of an utterance in a conversation interprets, either correctly or incorrectly, the "action", or intention, embodied in the utterance.

Consider the following facts: it takes over $600 \mathrm{~ms}$ to plan and execute the shortest turn-attalk..., while on average the gaps between turns are around $200 \mathrm{~ms}$, depending a bit on the language... This entails that B must plan his or her turn well before the prior speaker A's is finished. (Levinson, 2013, p. 103)

This indicates that the course of at least some conversations is unpredictable. It is important, therefore, to realize that instructional designers don't actually design conversations per se: "designed instructional conversation" may be somewhat of an oxymoron in the idealized sense, because among the important characteristics of any conversation is some degree of spontaneity and unpredictability. Utterances in a conversation are normally formed to some extent at the time of the conversation, and instructional conversations can be made responsive in some degree to a constantly changing context. 
What designers can design is occasions for conversations, the circumstances and environments around conversations, rules or guidelines for the conduct of conversations, the context of actions leading up to conversations, and scaffolding rules to guide and discipline conversational exchanges. A designer can pick topics and create objects and tasks about which conversations can occur and pose questions that lead to conversations, and even plan in advance skeletal message structures that can be filled with content at the moment of instruction, but designers do not design the conversations themselves; they simply provide for conversational contingencies in advance. In essence, they design engines that occasion conversation.

\subsection{The Architectural Theory of Instructional Design: Introduction of terms}

The architectural theory of instructional design views instructional designs as an integrated combination of sub-designs that correspond to functional modules of the designed artifact. The sub-designs are referred to as "layers" of the complete design, and a designer decides which layers pertain to a given design problem. The architectural theory proposes seven major layers, or functional domains, of an instructional design: content, strategy, message, control, representation, data management, and media-logic. These are described in more detail in a later section.

Each layer presents a unique design challenge that is addressed in the terms of one or more design languages related to that layer that are mostly irrelevant to the design of other layers. Layer designs are formed to interact adaptively during instruction. During message layer design, broad strategic goals are decomposed into smaller tactical goals and a messaging plan is formed 
that prepares messages of different types that are eventually mediated through multiple media channels in the design of the representation layer.

For each layer, architectural design theory posits that there exists a body of design knowledge that includes the layer-specific design languages, layer-relevant design questions, digital tools, design practices, design processes, a body of literature, and most importantly, layer-relevant instructional theory. There is sufficient overlap among the layers to allow design team members from different specialties to work together to integrate their layer designs into a coherent whole.

Literature from disparate fields supplies relevant theory and a set of language terms for message layer design. This monograph explores the development of these terms over time and connects them with a body of conversation theory from outside the instructional design field that supplies an architectural structure for layer designs. We build our case for validation of the message layer by citing work from instructional theory, conversation theory, research in the learning sciences, intelligent tutoring system research, and K-12 education. Within this literature, we demonstrate the existence of the message as a structural abstraction, a design construct, and an independentlydesignable entity. As we trace the development of the message construct historically, we show that it has remained remarkably stable over time, independent of changing psychological, educational, and technological fashion.

\subsubsection{What kind of theory?}

The architectural theory of instructional design is a technological theory - a theory of how natural forces and energies can be re-directed and focused purposely through design structure for 
the achievement of desired purposes. The term theory is not used here in the sense of scientific theory, which seeks explanations for natural phenomena. In a paper titled "Explore, Explain, Design”, Gibbons and Bunderson (2005) describe how theories are useful tools in all areas of human knowledge creation, including science, natural history, and design/engineering. The term "theory" is used here in its technological (design/engineering) sense.

The nature of technological theory is that it is used to generate design possibilities. The bestknown expression of this position is Simon's Sciences of the Artificial (1999), in which he describes application of technological theories in the fields of architecture, computer science, and engineering. In the field of aeronautical engineering, Vincenti (1990), sharing this view, enumerates several types of knowledge that designers generate and then apply in the design of new artifacts. Baldwin and Clark (2000), who also recognize this perspective, provide an indepth case study of the engineering at IBM that applied technological theory in the creation of a layered, modular line of computers, the IBM 360 family. In their interesting account, Baldwin and Clark show how this application of technological theory gave birth to the layered design paradigm that made possible the mass-produced personal computer as we know it today.

\subsubsection{Why an architectural approach?}

Architectural design theory makes it possible for design teams to employ specialized knowledge and tools to the design of complex artifacts, which cannot be created by a single designer alone. 
Stewart Brand makes a simple case for architectural design theory in How Buildings Learn:

What Happens After They Are Built (1994). He shows how advancing age overtakes a building almost as soon as it is built due to the uneven aging process of its different layers. He explains:

A design imperative emerges: An adaptive building has to allow slippage between the different-paced systems of Site, Structure, Skin, Space Plan, and Stuff. Otherwise the slow [changing] systems block the flow of the quick ones, and the quick ones tear up the slow ones with their constant change. Embedding the systems together may look efficient at first, but over time it is the opposite, and destructive as well. (Brand, 1994, p.20, emphasis in the original)

The architectural theory of instructional design allows members of an instructional design team to apply the skills, knowledge, and design theories pertaining to different layers of a design collectively to create artifact plans whose parts can age at different rates non-destructively. This approach to design is beneficial for instructional designs because it allows functional elements of a design to be modularized and combined in different configurations, according to the same principles that make it possible for you to design and organize a home network integrating modems, hubs, connections, and other kinds of devices according to your own functional needs.

\subsubsection{The design layers}

The architectural theory of instructional design proposes seven functional layers of an instructional design that correspond with seven functions carried out by virtually all instruction. These are: 
- Content layer-The layer where partitioning, scoping, and organization of content structures are specified. This layer expresses the assumptions of the designer about ontological organization, subdivisions, and groupings of subject-matter elements, including meaningful interrelations among conceptual and action-related entities.

- Strategy layer-The layer where instructional events are specified and at least twelve qualities are assigned to each event (Gibbons, 2020). This includes specifying the setting where instruction will take place, the social organization, participant roles, activities, patterns for interaction, rules for sequencing, and many other qualities.

- Control layer-The layer where learner controls and their effectivity during instruction are specified. This layer deals with the assignment of choice, control, initiative taking and the learner's means for acting.

- Message layer-The layer where the intentions of an instructional strategy become parsed and mapped to message structures that can be employed in conversational exchanges.

- Representation layer-The layer where messages become media-channeled, synchronized, and mapped to existing resources or linked to a representation generator.

- Data Management layer-The layer where rules for data collection, management, analysis, and reporting are specified. Data collected are used to support the learner's attempts at becoming self-directed and, short of that, to provide the strategy layer with recommendations and directions as needed.

- Media-Logic layer-The layer of the design for executing, with the learner, all of the functions of all the other layers, whose actions are invisible to the learner except for the representation layer. 
Architectural design theories (normally called functional design theories) have been found valid and useful in technological design fields outside of instructional technology. Our purpose in this monograph is to demonstrate the applicability and validity of one functional layer of a functional, (architectural) theory of instructional design. A comprehensive expression of the theory is given in Gibbons (2014). Previously published works argue the validity of three of the other design layers described by the theory: the content layer (Gibbons, Nelson \& Richards, 1999a; Gibbons Nelson, \& Richards, 1999b; Gibbons, 2000; Gibbons, 2001; Gibbons 2014; Helps, 2007), the strategy layer (Gibbons, 2020), and the control layer (Gibbons \& Langton, 2016). Three other layers that provide essential support services remain to be validated.

How are the functional layers derived? They are derived from: (1) design experience, including evolving patterns of design team organization, (2) the existence of communities of practice and professional organizations formed around specialized design team functions, (3) the existence of specialized tools, procedures, and design languages used by design team members, (4) the existence of bodies of instructional design theory appropriate to some functional design areas but not all design areas, and (5) successful patterns of design modularization, particularly in the design of simulations and intelligent tutoring systems.

The layers we name are neither absolute, nor do we make a claim of "truth." The pertinent questions are a matter of design judgment and utility: "Do they lead to designs and artifacts that can operate within a rapidly changing human and technological environment without being destroyed by change?", "Do they produce more effective and adaptable designs?", and "Do they 
expedite increasingly sophisticated designs and increase the efficiency of designing and producing artifacts?" These are key questions in any technological design field.

Could a different list of functional layers be generated and validated? The answer to this question is that there could be and probably will be different layer schemes in the future. Since layers are a response to increasing artifact complexity, as new technological devices, concepts, and theories are devised (e.g., machine learning), they will disrupt current conceptions of artifact functional architecture by introducing a new function at some level of the design. A historical example of this is found on the rapidly evolving technologies of the representation layer. Where once the technologies of the computerized instructional designer included primarily the authoring language/system and its primitive display creation tools, now there are so many subspecialties that are part of designing in which a single designer is not likely to be competent. The complexity of the artifact and the skills required to design and create an artifact with the maximum life expectancy have simply exploded, creating the need for new sub-specialty layers, each with its own design languages, typical problems, processes, tools, and specialized design theories. Therefore, the configuration of layers and the designation of new sub-layer specialties will continue to be a highly strategic process for the designer.

Layers represent a source of designer advantage. If one designer can "see" a functional area that other designers can't see, then it adds advantage to the designer's craft. Skinner "saw" an advantage in conversational interactions, leading to the tacit recognition of a type of message layer. His theory also saw the advantage of giving the learner opportunity to respond - the origin, the formal recognition, and the foregrounding of a control layer. Though Skinner's theories are 
no longer dominant in design, the message and control layers that surfaced in the thinking and practice of program designers persists at least tacitly in the question: "How can I create more effective interactions?" Likewise, once designers began to pursue conversational instruction using machine intelligence, the role of collected data from past interactions in guiding future choices of the tutoring system led to the emergence of a data-related functional area of designs whose purpose was tracking the learner's knowledge state against an idealized knowledge state. The data management functional layer of designs then became visible as a function to designers, even those not designing intelligent tutors. Today, that function (which was always implicit in the teacher's grade book) is visible to the technology designer as an advantage.

\subsection{Layers During Design and Instruction}

During design, layers are used to focus the work of design specialists, who work independently and then together in alternating cycles, first to fashion design concepts within layers, and then to integrate layer designs into a unified, cohesive whole.

\subsubsection{Layers During Design}

During design, team specialists alternate between framing a design within their own layer and working to harmonize their plans with designers of other layers until they arrive at a unified, workable, complete design that integrates the functions of all layers, creating a seamless user experience. Traditional approaches to design focus on a generalized order of design decisionmaking specified by a design process. When layer principles are used, traditional methods of managing design projects are not set aside, but the order in which a more detailed level of design processes are initiated can differ greatly, with different design problems calling for a unique 
design order that depends on the constraints and resources attached to the problem. Different design problems present the design team with priorities and constraints that define a design space left available to the designer of each layer, and a priority order of decisions.

Constraints may include restrictions on certain layers. A specific instructional strategy may be pre-determined by a client, or a specific representation medium or combination of media. Any layer may be constrained. Constraints include resource limitations as well, including the unavailability of skilled designers, tight deadlines, budget constraints, or the requirement to accommodate research within an experimental design. Priorities may include emphasis on a style, tone, image, the production quality of the artifact, or experimentation with innovative forms of interaction. A client may hope that learners will carry away from the learning experience an impression, a set of values, or certain metacognitive skills. Such desiderata may also give precedence to design decisions within one or more layers and the ordering of decisions within layers.

During design, the decisions made relative to one layer impact other layer designs. Once decisions are made tentatively in one area of a design, they become new constraints imposed on further decisions (See Gross et al, 1987), either within the same layer, or across layers. This process of addressing and creating constraints continues until all relevant decisions have been made and all constraints have been dealt with as well as possible. Excellent detailed studies of this process are found in Bucciarelli's Designing Engineers (1994), Pool's Beyond Engineering (1997), and Kidder's The Soul of a New Machine (2000). The major implication of decision orders and constraints during design is that a design advances toward completion on several 
fronts at once, determined primarily by the priority of decisions made within each layer. This means that design team members work both independently and apart, designing within layers, and then frequently reconciling individual layer designs into the integrated whole.

\subsubsection{Layers During Instruction}

Once a design is embodied, the relationships among layers changes and begins to operate in the manner of an instructional factory, or production line — especially in live, tutoring, or machine intelligence forms of instruction. The functions of the strategy layer take primacy during instruction, managing and coordinating the operations of the other layers.

The technology-based delivery case is straightforward. Following the learner's expression of a response using designed controls, the strategy layer's interpretive rules interpret the response according to the intelligent or fixed rules given by the designer. At this point, depending on the designer's planning, the strategy function either: (a) consults its rules to select appropriate preformed messages and pre-formed representations, or (b) generates appropriate messages from atomistic elements and generates representations for them according to a set of representational rules.

In the case of live instruction, an instructor observes the responses of a learner through a multichannel sensory system. This input is processed rapidly through a set of powerful rules peculiar to the instructor. The instructor's strategic plans determine a course of action and decompose it into a to-do list of points to make and actions to take. These intentions (the messages to be conveyed) are translated by the instructor's experience into words, diagrams, language, and 
gestures. In this basic mechanism there is no difference between the operations of the technology and the instructor. Strategy takes primacy, it is broken down into an action plan, and then it is given expression. In this sequence, the message is an essential link. The sensory and representational advantages of the instructor aside, the differences between live and technologybased instruction arise from the quality of the rules used to generate the strategic, messaging, and representational wisdom of the designer or instructor.

\subsection{The Message Layer in Relation to Other Layers}

Just as the message layer offers the message construct as a core building block for achieving conversational purposes, other layers likewise rely on constructs specific to themselves for achieving their purposes. During instruction, the quality of the learner experience can depend on how the designer organizes and gives values to the constructs within each layer and how well these are synchronized across layers. The designs of the strategy layer and representation layers, along with the control layer, are especially important to the message layer because their alignment is responsible for the chain of events that conveys the intention of the instructor/designer through to representations and interactions the learner can experience.

Strategy layer. Message design is accomplished through a process of decomposition and translation of high-level macro-strategic structures into smaller, tactical, micro-strategic elements - messages - that can be matched with conversational structures. Message elements, when designed and arranged within conversational structures, are the low-level means of carrying out higher-level strategic purposes such as "practice" and "provide feedback,". 
When design of the message structure is omitted as an intermediary step for the conversion of strategies to representations and learner actions, designers, writers, and editors are often left with the problem of "making it interactive" after the fact. Without message layer design, strategy and message layers are conflated. Designers and writers are left to capture designs in textual or graphic forms that are close to the mostly textual form in which they end up being represented to the learner. "Writing a lesson" and "writing a script" are common designer activities that blind designers to the message layer constructs out of which interactive conversational structures could be built. This bridging function performed through deliberative message design is even more important for instructional forms that are adaptive and intelligent, than it is for human-delivered instruction.

Representation layer. Message design precedes representation layer design, because the representation layer, which is the only layer visible to the learner's senses, derives its structure from the properties of the message to be expressed. Message layer designs exist in the form of abstractions that express information, significant interaction, and emotional value. Conversational message elements are transformed by representation rules to create media expressions. As designers are able to separate the representation from the message being represented, they find it possible to consider more sophisticated representations directly expressive of the original macro-strategic intent. Skilled human instructors do this automatically, although those with less skill may benefit from explicit planning that emphasizes this relationship. 
It is important to keep the difference between the message layer and the representation layer clearly in mind throughout the discussion of the message layer in later chapters. Messages are abstract and have no embodiment that is visible to the learner. They are intentions to be communicated. Because they are abstract, pre-representation messages are easy to confuse with the representation elements that give them visibility to the senses. In Artificial Intelligence and Tutoring Systems Wenger (1987) dwelled at length on the relationship between unmediated messages (which he called "internal representations") and mediated representations (which he called "external representations"). He was especially concerned with the degree of fidelity between the representation and the original intentions of the message. He referred to this as the problem of "epistemic fidelity," referring to how well, truthfully, accurately, and completely the external representation mirrors the intent of the internal representation (See Wenger, 1987, p. 312-317).

\subsection{Conclusion}

The purpose of this chapter has been to link the concept of instruction as a conversational process with the constructs and structures provided by an architectural theory of instructional design: specifically one architectural layer of a design: the message layer. The stage has been set, therefore, for an extended discussion in subsequent chapters of the theoretical, research, and practical roots of the message layer and the message construct as a thought tool for designers to consciously facilitate conversational designs.

\section{References}


Baldwin, C. \& Clark, K. (2000). Design rules: The power of modularity. Cambridge, MA: MIT Press.

Brand, S. (1994). How buildings learn: What happens after they're built. New York: Penguin.

Brooks, F. P. (2010). The design of design: Essays from a computer scientist. New York: Addison-Wesley Professional.

Bucciarelli, L. L. (1994). Designing engineers. Cambridge, MA: MIT Press.

Fowler, M., \& Beck, K. (1999). Refactoring: improving the design of existing code. AddisonWesley Professional.

Fox, B. A. (1993). The human tutorial dialogue project: Issues in the design of instructional systems. Hillsdale, NJ: Lawrence Erlbaum Associates.

Gibbons, A. S. (2001). Model-centered instruction. Journal of structural learning and intelligent systems, 14(4), 511-540.

Gibbons, A. S. (2014). An architectural approach to instructional design. New York: Routledge. 
Gibbons, A. S. (2020). What is instructional strategy? Seeking hidden dimensions. Educational technology, research and development. Published online: 3 September 2020. Available at: https://rdcu.be/b6Ldw. https://doi.org/10.1007/s11423-020-09820-2.

Gibbons, A. S. \& Bunderson, C. V. (2004). Explore, explain, design. In K. Kempf-Leonard (Ed.), Encyclopedia of social measurement. New York: Elsevier Science, 927-938.

Gibbons, A.S. \& Langton, M. B. (2016). The application of layer theory to design: The control layer. Journal of computing in higher education, 28, 97-135. http://scholarsarchive.byu.edu/facpub/2968

Gibbons, A. S., Nelson, J. S. \& Richards, R. E. (1999a). Theoretical and practical requirements for a system of pre-design analysis. White paper prepared for the Human-Systems Simulation Center of the Idaho National Engineering and Environmental Laboratory, Idaho Falls, ID. https://scholarsarchive.byu.edu/facpub/1330

Gibbons, A. S., Nelson, J. S. \& Richards, R. E. (1999b). Model-centered analysis process (MCAP): A pre-design analysis methodology. White paper prepared for the Idaho National Engineering and Environmental Laboratory, Idaho Falls, ID. https://scholarsarchive.byu.edu/facpub/1328. 
Gibbons A. S., Nelson, J. S. \& Richards, R. E. (2000). The nature and origin of instructional objects. In D. Wiley (Ed.), The instructional use of learning objects. Bloomington, IN: Association for Educational Communications and Technology, 25-58.

Gibbons, A. S. \& Rogers, P. C. (2009). The architecture of instructional theory. In C. M. Reigeluth \& A. Carr-Chellman (Eds.), Instructional-design theories and models, Volume III. Mahwah, NJ: Lawrence Erlbaum Associates.

Goldstein, I. P. \& Bobrow, D. G. (1980). A layered approach to software design. Report no. CSL-80-5. Palo Alto, CA: Xerox Corporation.

Gross, M., Ervin, S., Anderson, J. \& Fleisher, A. (1987). Designing with constraints. In Y. Kalay (Ed.), Computability of design. New York: John Wiley \& Sons, 53-83.

Helps, R. (2007). Dancing on quicksand gracefully: Instructional design for rapidly evolving technology courses. SIGITE '07: Proceedings of the $8^{\text {th }}$ ACM SIGITE conference on information technology education, 1-8. https://doi.org/10.1145/1324302.1324304.

Heritage, J. (2013). Epistemics in conversation. In J. Sidnell and T. Stivers (Eds.), The handbook of conversation analysis. West Sussex, UK: Wiley-Blackwell, 370-394.

Kidder, T. (2000). The soul of a new machine. New York: Back Bay Books. 
Levinson, S. C. (2013). Action formation and ascription. In J. Sidnell and T. Stivers (Eds.), The handbook of conversation analysis. West Sussex, UK: Wiley-Blackwell, 104-130.

Pool, R. (1997). Beyond engineering: How society shapes technology. Oxford, UK: Oxford University Press.

Rheinfrank, J. \& Evenson, S. (1996). Design Languages. In T. Winograd (ed.), Bringing Design To Software. Reading, MA: Addison-Wesley Publishing Company.

Rogoff, B. (1990). Apprenticeship in thinking: Cognitive development in social context. New York: Oxford University Press.

Siegel, D. J. (1999). The developing mind: Toward a neurobiology of interpersonal experience. New York: Guilford Press.

Simmonds, I. \& Ing, D. (2000). A shearing layers approach to information systems development. In M. Huhns and I. Gasser (Eds.), The structure of ill-structure solutions: Boundary objects and heterogeneous distributed artificial intelligence. Distributed artificial Intelligence, Volume II. San Mateo, CA: Morgan Kauffman.

Simon, H. (1999) The Sciences of the Artificial (3 ${ }^{\text {rd }}$ ed.). Cambridge MA: MIT Press. 
Vincenti, W. G. (1990). What Engineers Know and How They Know It: Analytical Studies from Aeronautical History. Baltimore, MD: Johns Hopkins University Press.

Vygotsky, L. S. (1978). Mind in society: The development of higher psychological processes, edited by M. Cole, V. John-Steiner, S. Scribner, and E. Souberman. Cambridge, MA: Harvard University Press.

Wenger, E. (1987). Artificial intelligence and tutoring systems: Computational and cognitive approaches to the communication of knowledge. Los Altos, CA: Morgan Kaufmann. 


\section{Chapter 2 \\ Conversation Theory and the Message Construct}

\subsection{Conversation Analysis and Conversation Synthesis}

The purpose of this chapter is to demonstrate that the message construct provided by the architectural theory of instructional design aligns with constructs supplied by an analytic conversation theory that provides tools for research and design pertinent to instructional conversations and opens new avenues for exploring the design of conversational structures for instruction.

Scientific research in developmental psychology (e.g., Vygotsky, 1978; Rogoff, 1990; Siegel, 1999) shows that, from infancy onward, conversational interactions with caregivers set the pattern for human social and learning interactions with the experienced world, which includes interactions during both formal and informal learning. The claim that instruction is a form of conversation is a technological hypothesis, not a scientific claim, and is therefore not falsifiable. The success of many independently developed instructional approaches that have historically applied the hypothesis (e.g., human tutoring, intelligent tutoring, and many classroom conversation-based methods) demonstrates that in at least some cases the hypothesis is valid and suggests that the boundaries of its application should be explored.

\subsection{A Generalized Model of Conversation}

Winograd and Flores (1986) proposed a generic model of human-computer interaction in the form of a conversational pattern that can be used to describe human-human conversational interactions as well (see Figure 1). The value of this well-known model, which has been used 
extensively in studies of human-computer interaction, is that it demonstrates that generic structures can be detected underlying the otherwise chaotic-seeming flow of everyday conversations. In this chapter even more precise structural principles of conversation structure are discussed.

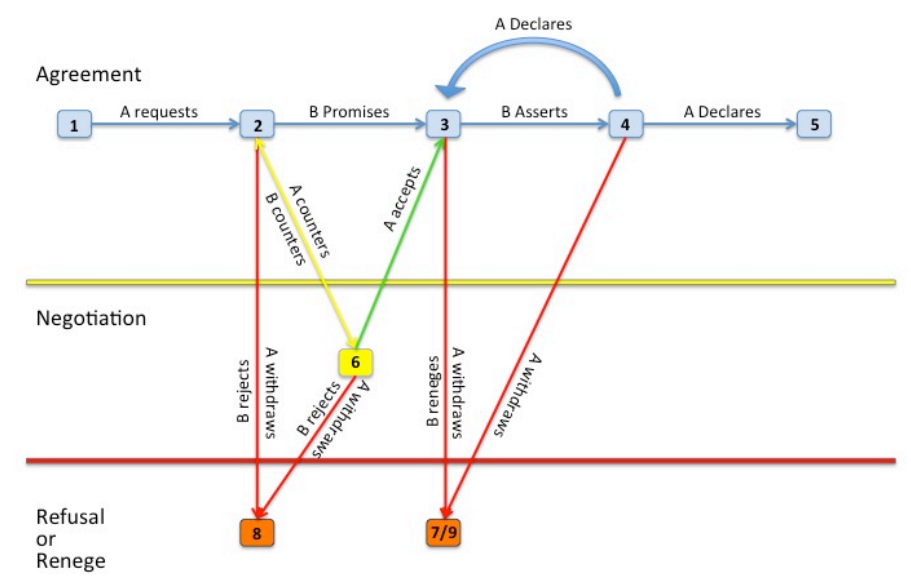

Figure 1. A generic model of human-computer interaction that can also be used to typify human-human conversational interactions as well. (After Winograd \& Flores, 1986.)

The Winograd-Flores model recognizes that humans engage in goal-oriented interaction through offers, requests, assertions, and declarations that are answered by acceptances, rejections, counter-assertions, and counter-offers. The goal-orientedness of these conversations is evidenced by the fact that when one or both conversants fulfill, reject, or give up their goals, conversation ends. 
Flores et al (1989) elaborated this model in extensive detail for a patent filing under the title

"Method and Apparatus for Structuring and Managing Human Communications by Explicitly Defining the Types of Communications Permitted Between Participants” (Flores et al, 1989). The simple pattern from Figure 1 can be found at the core of the more elaborated model, which describes more accurately the more convoluted path of most conversations.

\subsection{Conversation Analysis vs. Conversation Synthesis}

The Winograd-Flores model is valuable in many respects, because it describes interaction and negotiation processes at several recursive levels of organization, and applies equally well to human-human, human-computer, and computer-computer conversations. Its most valuable contribution our concerns here is that beyond being analytic, it is also synthetic. That is, the model not only supplies a pattern for understanding conversational interactions, it also supplies a general pattern for generating conversational interactions, systems of utterance, and elements and rules for organizing them. Though there are numerous systems for analyzing existing conversations, few can support their generation.

In Chapter 1 we suggested that instructional designers do not design adaptive conversations per se. We proposed instead that they design occasions, circumstances, environments, rules, guidelines, contexts of action, scaffolding processes, topics, objects to talk about, and tasks to perform that occasion conversation. A designer can pose questions and anticipate responses, but the texture of the resulting conversation depends on the granularity of the elements the designer has planned for. Grossly-defined elements result in highly predictable conversations with little adaptivity to the learner's state. Most designers create interactions that are fixed within a 
predictable matrix of expected assertions and responses. This has become an accepted standard for technology-based instruction because it can appear flexible to the learner within a certain tolerance limit of expected responses. Instructional conversations of this kind are relatively easy and economical to design and develop. However, designs of this type most frequently target specific subject-matter and pay less attention to the establishment of metacognitive skills such as problem-solving, inquiry, and self-directed learning. Something of the granularity issue can be seen in systems of tightly scripted teacher-led instruction as well (see, for example, Gunter et al, 1998; Ede, 2006; Plavnick et al, 2015).

Adaptive forms of instruction expand the range of learning goals that can be pursued but require more finely-grained design elements and some degree of human or program intelligence for the logic generating the conversation. The difference is not a difference of type but of degree, since adaptivity is not binary. In technology-based products the price of higher adaptivity is more finely-grained analysis of message elements, more intelligent real-time selection of the elements, and generation of larger combinations and sequences of those elements at the moment of need. However, one does not have to create a full-featured intelligent tutor to increase adaptivity. For this reason, we contend that the message construct should be considered by designers in general as the atom, or elementary particle, for compounding more adaptive, more conversational interactions.

A single conversational turn (utterance) during instruction contains one or more messages. For example, we suggest this typical feedback turn can be seen as multiple concatenated messages that are shown in angle brackets: 
$<$ Incorrect $>$

$<$ You missed one step that resulted in an incorrect answer $>$

$<$ A demonstration of the correct step is available for you to see $>$

$<$ Touch $<$ control-namel $>$ to see this demonstration $>$

$<$ Touch $<$ control-name $2>$ to move on $>$

Each element in angle brackets conveys a specific intention of the designer to communicate. The elements are separated because they are modular and can be selected or de-selected according to designer judgment. The number of individual message elements combined into a conversational turn depends on the set of elements the designer has chosen as elementary particles and the rules the designer has created for choosing and arranging those elements under different conditions. The possible number of combinations increases as the number of elements increases and the rules for combining them become more nuanced. Elements and choice rules are part of a human instructor's repertiore, but even these can be improved through thoughtful advance preparation.

It is useful to bring up again the message-representation divide described at the end of Chapter 1; the crafting of messages proceeds independently of the assignment of resources or rules for mediation. For example, the message " $<$ Incorrect $>$ " might be represented by a loud buzzer, a graphic, a voice, or all of these together. The other messages might be represented through text, an arrow or other emphasis symbol, through some form of motion, or by voice. Just as there are rules for creating messages, there are separate rules for converting message intentions into media 
representations. This separates the thoughtful consideration of message design from what we would hope would be an equally thoughtful—and independent—representation design.

\subsection{A Theory of Conversational Structure}

Descriptive theories like that of Winograd and Flores help us analyze and understand conversational structures. However, theories that support rule-driven synthesis of conversations are few. Moreover, most analytic theories are biased by association with a purpose, philosophy, or viewpoint. To be useful, a model for conversation design must be content-agnosticindependent of a particular psychological theory or philosophical worldview that might unintentionally temper or bias the designs for which it is used.

Conversation analysis (CA) is an example of a content-agnostic theory of conversation. Sidnell (2016) describes CA as the study of the nature of conversations using precise research methods in search of recurring structural patterns. The goal of CA is to understand more deeply the patterns and structures of conversational interactions, but not their psychology. The motive for CA research is to provide analytical tools that avoid biasing analysis for others who study human verbal and gestural expression. Because its goal is content-free structural descriptions of conversations, $\mathrm{CA}$ is usable as a tool for synthesizing conversations as well.

CA research examines speech acts, silences, gestures, expressions, posture, and direction of gaze. CA is not the study of semantics and meanings, it is an approach to describing in detail "what is there" in conversations and how conversational structures allow people to anticipate each other's meanings (Maynard, 2013). According to CA, conversations consist of morphological 
structures - words, phrases, clauses, and sentences. These structures that can be used

strategically. This system of structure is used to advance conversations toward the satisfaction of jointly-held goals.

CA research describes conversations in terms of atomistic elements combined at several levels of aggregation. In this chapter, CA will be used as an example to demonstrate how a theory of conversation analysis can also be relevant as a theory of conversation synthesis when coupled with an instructional design theory expressed in similarly atomistic terms. We do not promote CA as a correct theory, but we do use CA's structural paradigm to demonstrate that an architectural theory of instructional design can support the design of instructional conversations.

Messages consist of unexpressed intentions. Before the speeches and gestures observed in conversations, we must assume that there exist in the mind of the agent intentions (prerepresentational intentions) to communicate something informational, strategic, value-laden, and/or emotive. As we describe conversation structures of CA in the sections that follow, remember that we are describing them in terms of their abstract pre-representational intentions and not their mediated form.

\subsubsection{CA and Morphological Elements of Conversations}

According to CA, morphological elements of conversations include words, phrases, clauses, sentences, and groups of sentences. In conversations these easily-recognizable surface features are arranged in units called turns (Drew, 2013). Turns are defined temporally. Normally a turn 
ends when one person stops talking and another begins, though a turn may be interrupted or talked over by another conversant. A turn may also end when one conversant remains significantly silent or makes a gesture.

\subsubsection{How Strategic Intentions Are Expressed Through Morphological Elements}

According to CA theory, conversational goals are achieved by combining morphological elements in different patterns and combinations of patterns. Combinations of morphological structures arranged strategically facilitate the conduct of conversations on specific topics. Morphological structures supply a framework that allows conversants to anticipate and understand each other, regardless of the topic of conversation. Five types of morphological CA structure are described here that can be used to accomplish strategic purposes: turns, messages, adjacency pairs, sequences, and projects.

\subsubsection{Turns, messages, and actions}

A conversational turn is an utterance that ends with a pause or an interruption. CA describes turns as the most fundamental constituent of conversations. (Though as we have shown in the example above, turns may be composed of multiple messages.) A single turn in a conversation may be as simple as a single word or sentence, or perhaps nothing more than a nod of the head. Most turns are longer, however, and consist of multiple morphological structures (sentences, phrases, words, sounds, gestures) and as we will show, strategically-chosen messages.

Turns have purposes. Each turn (and each message within a turn) is selected to perform a particular strategic action or group of actions that can be understood: "actions like requesting, 
inviting, granting, complaining, agreeing, telling, noticing, rejecting, and so on" (Schegloff, 2007, p. xiv, quoted in Levinson, 2013, p. 104). Combinations and sequences of actions serve as the strategic structures of conversations. Table 1 shows how the complete action performed by a feedback turn can be analyzed in terms of actions performed by constituent messages.

Table 1. Analysis of a conversational turn from instruction in terms of the intended actions performed by each of its constituent messages.

\begin{tabular}{|c|c|c|c|}
\hline Message & Intended action & $\begin{array}{c}\text { Possible } \\
\text { representations } \\
\text { (technology-based } \\
\text { instruction) } \\
\end{array}$ & $\begin{array}{c}\text { Possible } \\
\text { representations } \\
\text { (human-based } \\
\text { instruction) } \\
\end{array}$ \\
\hline$<$ Incorrect $>$ & $\begin{array}{l}\text { Supply error feedback for last } \\
\text { response }\end{array}$ & $\begin{array}{l}\text { Bzzzt! (buzzer) or } \\
\text { Ding! (bell) or } \\
\text { Text in red color }\end{array}$ & $\begin{array}{l}\text { Teacher shakes head } \\
\text { (as in "no"), while } \\
\text { saying "Not quite...." }\end{array}$ \\
\hline $\begin{array}{l}<\text { You missed one step that in some } \\
\text { problems could result in an } \\
\text { incorrect answer }>\end{array}$ & Name the error & $\begin{array}{l}\text { Your answer is } \\
\text { incomplete. } \\
\text { (text on screen) }\end{array}$ & $\begin{array}{l}\text { "You missed a step } \\
\text {..." }\end{array}$ \\
\hline $\begin{array}{l}<\mathrm{A} \text { demonstration of the correct } \\
\text { step is available for you to see }>\end{array}$ & Afford remediation & $\begin{array}{l}\text { May I show that step? } \\
\text { (text on screen) }\end{array}$ & $\begin{array}{l}\text { "I could point it out - } \\
\text { " }\end{array}$ \\
\hline $\begin{array}{l}<\text { Touch }<>\text { to see this } \\
\text { demonstration }>\end{array}$ & Afford acceptance of remediation & $\begin{array}{l}\text { Yes (text with check } \\
\text { box) }\end{array}$ & "—if you like —" \\
\hline$<$ Touch $<>$ to move on $>$ & Afford rejection of remediation & $\begin{array}{l}\text { No (text with } \\
\text { checkbox) }\end{array}$ & $\begin{array}{l}\text { "-or we could move } \\
\text { on." }\end{array}$ \\
\hline
\end{tabular}

Table 1 demonstrates how multiple messages within a turn, each of which can later be represented in multiple ways, carry out a higher-order instructional strategy — a simple feedback turn that can be summarized as, "identify that an incorrect response has been given and provide options for remediation, or moving on". ${ }^{1}$ Multiple messages that make up a single turn are used to carry out strategic instructional purposes that work at a higher level than the individual messages. This accords with Levinson's statement that “a turn may perform two, perhaps three, 'main jobs' [actions] at once....' (Levinson, 2013, p. 107).

\footnotetext{
${ }^{1}$ This demonstrates how strategy layer goals fragment to produce micro-strategic and then messaging goals. The relationship between the strategy and message layers can be seen more clearly here. Messages carry out the purposes of larger, fragmented blocks of strategy that represent instructional purpose.
} 
According to Levinson (2013, p. 122), the number of possible action types is very large. Action types are culturally-acquired, and the number of actions a person recognizes grows throughout life. Based on maturity and experience, different people are able to recognize different action types. This point is important point for conversational designers, since their audiences can vary widely in their abilities to comprehend different conversational actions. Some actions are easy to recognize; others are more subtle and nuanced.

Consider, for example, the number of request-making actions recognized by a young child, compared with the number of request-making actions recognized by a mature adult. A child may not recognize that a direction to act is being given until a message conveys a direct order; an adult may recognize a direction being given as an indirect question. For example, at a picnic, someone may ask, "Does someone see the salt?" and a child respond, "I see it over there," while an adult would likely respond by taking the action of passing the salt. Learners can respond to actions that they recognize. Part of learning consists of learning new actions. Instructional designers must be sufficiently aware of the populations for whom they design and the actions they most likely recognize, because actions conveyed in messages and turns are part of the engine that moves conversations forward; they can represent sources of communicative power or sources of confusion.

\subsubsection{Adjacency pairs.}

According to CA, the next largest basic unit of conversation is the adjacency pair: one conversant takes a turn and makes an utterance, and the other responds in their turn with a second utterance. Adjacency pairs are strategic. They represent one round-trip exchange in a 
conversation. The actions in the second turn of an adjacency pair normally respond strategically to the actions contained in the first one. If one turn asks a question, the second turn will probably be an answer; if the first turn is an offer, the second will probably be a refusal, an acceptance, or an offer to negotiate. The Winograd and Flores (1986) model of conversational interaction in Figure 1 illustrates in simplified form the strategic function of adjacency pairs in CA.

Adjacency pairs are strategic in a second way. They are a basic unit for carrying out diagnostic assessments. An instructional conversation is directed toward the attainment of instructional goals. Progress toward goals can be constantly monitored through responses. Diagnosis works both ways in a conversation. Either conversant may detect a misunderstanding in the other, which may lead to a repair of the misunderstanding. Frequent, small performance assessments can be carried out through the means of adjacency pairs. Thus through a continuous feedback loop action a conversation becomes self-correcting and adaptive.

\subsubsection{Sequences.}

Turns and adjacency pairs occur within larger combinations called sequences. Sequences are best described as a string of adjacency pairs that pursue the same goal: one that is larger than can be accomplished by a single adjacency pair. Thus, sequences permit understanding to be built in incremental steps - multiple back-and-forth exchanges in which there may be multiple questions and answers that lead to an alignment of understanding and the attainment of a conversational goal.

Here is a sequence showing goal selection during a tutoring session: 
S: I did well on the last test, but I missed a few questions.

T: Which ones? Can you remember?

S: The ones on factoring.

T: What kind of feedback did you receive? Did it explain where you made the mistakes?

S: No. There was no explanation. Just a score.

T: Do you know where you went wrong?

S: I don't get the whole idea, basically.

T: So, would you like to spend some time on factoring?

S: Yes.

The result of the sequence is a shared instructional goal. This next sequence has the goal of diagnosing the problem.

T: Show me the kind of question you had problems with.

S: Here's one. (Writes it down)

T: What answer would you give to this?

S: I would say... (writes an answer)

T: Could you show me your steps?

S: Sure. (Writes out steps)

T: OK. How did you get from this (pointing) to this (pointing)?

At this point a dialogue might follow that employed any number of instructional methods to include Socratic tutoring, direct lecture, demonstration, or some other method. 
One of the values of sequences is that they can be interrupted by other sequences when a new goal is discovered that must be attained before the original goal can be satisfied. In this case, one sequence is temporarily suspended while the new one is pursued, and then resumed once the new goal is satisfied. The following sequence illustrates that.

S: ... So I did this next...

T: Wait. Why did you do that?

S: Because this (pointing) is a factor of that (pointing).

T: But it's not a factor is it?

\section{S: Isn't it?}

[Original sequence is suspended]

$\mathrm{T}$ : No, because a factor implies multiplication of terms.

S: So those are not factors?

T: No, because there is a plus here (points), which means they are not multiplied.

S: Oh. I get it.

[Resuming the goal of the original sequence]

T: So, knowing that, what step would you take next?

S: I'd do this.

T: Right.

S: And get this.

T: Right.

S: And that's the right answer?

T: Yeah.

[Initiating another sequence with the same goal as the first] 
T: Now let's try another one...

Sequences are interruptible and resumable. They constitute moveable and re-orderable chunks of strategy that allow lower-level strategic goals to interrupt higher-level goals, making possible a process for the repair of misunderstandings. In Chapter six, repair is explained in more detail as a key process that gives forward momentum to instructional conversations.

The example above illustrates the interruption of one goal-pursuing conversational sequence momentarily to pursue a lower-level goal, followed by the resumption of the higher goal: one conversational sequence interrupting another digressively but constructively. A repeated pattern of temporary goal suspensions of this type can result in the stacking of multiple goals and then their resumption in reverse order. We contend that this is the typical pattern of adaptive, conversational instruction because it is the typical pattern of conversations in general.

\subsubsection{Projects.}

Levinson (2013) describes a "project" as a level of conversational organization consisting of several sequences that take place in pursuit of a common goal. Projects consist of sequences of sequences that occur in an order determined at the moment of need. Levinson cites the example of a courtroom conversation in which a reluctant witness causes an attorney to initiate multiple sequences, coming at the witness with questions from different angles to obtain the desired testimony. This may involve the formation and suspension of multiple sequence goals in a seemingly disconnected manner to reach the higher-level goal of obtaining the desired testimony. 
Instructionally this may be represented by a learner who requires multiple explanations using different explanation patterns in order for a new concept to take root, or a learner who requires solving multiple multi-step problems of the same form in order to perfect solution skills for a particular class of problems. A project can persist across the span of one instructional session, multiple instructional sessions, or even an entire course. If a goal is not satisfied with one sequence, then the project may cause additional sequences to appear in subsequent conversations. This kind of goal continuation is typical in everyday teaching relationships, as most teachers and tutors normally have multiple open projects with their learners at any given point in time over the course of a semester.

\subsubsection{Non-verbal elements and emotional modifiers}

Some of the most important messages of live and tutorial instruction are most efficiently and effectively conveyed non-verbally. These include the instructor's desire to send messages of confidence, inspiration, approval, disapproval, calming, encouragement, or empathy. In live instruction and tutoring these non-verbal messages are frequently represented through facial expressions, gestures, postures, directions of gaze, voice inflections, coughs, sighs, and silences. These non-verbal messages are as much a part of conversational turns as verbal ones (Levinson, 2013). But these gestures are outward representations behind which stand messages. Our focus in this section is on messages and how they give rise to representations, especially those that are non-verbal and intended to convey feelings as well as information. Sometimes non-verbal messages purposely contradict verbal messages in the same turn to create more nuanced messages such as irony or veiled approval or disapproval. As Levinson describes it, "the unsaid haunts the said" (Levinson, 2013, p. 126). 
Capturing and integrating non-verbal or emotional message intentions is somewhat of a blind spot in contemporary instructional design practice. The emotion-related, personal aspects of instruction that are so naturally projected by live instructors and tutors are largely absent in technology-based designs and are frequently dealt with as an afterthought through superficial decorative graphics and text messages (often ending with an exclamation point!). Surface techniques that try to humanize instruction in this way are often the only recourse when using media devices that are not conversation-capable and therefore largely blind to the learner's momentary emotional state. ${ }^{2}$

The powerful emotional and informational impact that non-verbal, affect-related messages can deliver through appropriate representations is illustrated in the film $W A L L-E$ (see Stanton \& Reardon, 2008), a machine's love story expressed mainly through beeps and squeaks. The first half of the $W A L L-E$ script consists mainly of descriptive directions, such as, "small service robot diligently stacking trash", rather than speeches. WALL-E's sound effects are representations, not messages, which makes more apparent the line between the message and representation layers that is so difficult for designers to see. The wordless messages in WALL-E were designed prior to their representation, first in the form of a storyline, then in the form of gradually unfolding plot events, and finally in storyboards, but the message-laden script of WALL-E preceded the storyboards and the final visuals and sound effects.

\footnotetext{
${ }^{2}$ A case for the role of emotions in learning can be found in Norman (2004), Immordino-Yang (2015), Christianson (1992), and others.
} 
What are the benefits to being able to see this demarcation of layers? It is that the designer can consider and integrate the full range of messages and their expected impact before committing to the verbal, graphic, and non-verbal symbolic representations of all of the messages. Relying on message design first, before designing representations facilitates a more complete consideration of all of the aspects of message that must come together and work in unity in the representations - the informational and the emotional together. When designers of instruction fail to consider the full range of messaging intentions prior to representation design, then some representations, especially those that should have an emotional appeal of some kind, are in danger of becoming add-ons and decorations rather than an integral part of the design. This apparent in intelligent tutors that attempt to use still-life or mechanical graphic facial avatars to simulate the quality of a human presence for the learner.

In contrast, the STEVE animated instructional agent represents a disciplined demonstration of message integration in a production that senses the learner through action controls moment by moment, responding to learner questions and commands (Johnson \& Rickel, 1998). The STEVE design has built the non-verbal message-to-representation system into the same system that drives the verbal and graphic representations. In STEVE's design, there was clearly a thorough planning of the complete messaging system prior to the design of the representation driver. Evidence for this is found in the research base that supported STEVE's design of non-verbal gestures and direction of gaze (Rickel \& Johnson, 1999); facial expression and posture (Johnson, Rickel \& Lester, 2000). Likewise, WALL-E's voice inflections show this level of message planning (Stanton \& Reardon, 2008). Johnson \& Lester (2016) provide a twenty-year retrospective on the non-verbal message research of Johnson \& Rickel and its impact. 


\subsubsection{Epistemics, Strategies, and Diagnostic Assessment}

In virtually every conversation, some degree of knowledge imbalance exists between conversants (Heritage, 2013). The purpose of instructional conversation is the mutual exchange of information, feeling, and values to address imbalances in the knowledge, values, and/or emotional states of one or both conversants. The question for designers is how to identify existing imbalances for a particular learner.

In the last half of the twentieth century, instructional design literature advocated pre-testing prior to instruction, but the level of diagnostic testing became impractical in time and expense. Current instructional design literature does not emphasize diagnostic pre-testing as much as it used to. In an instructional conversation, however, it is vital that "speakers are able to 'keep score' of who knows what and when...." (Heritage, 2013, p. 374). This involves knowing:

What is known [by the other conversant], how it is known (through what method, with what degree of definiteness, certainty, recency, etc.) and persons' rights, responsibilities and obligations to know it (Heritage, 2013, p. 377, braces added, parentheses in the original).

New technological delivery and databasing systems and the possibility of conversational instruction with intelligent tutoring systems make the topic of diagnosis relevant again, but at a much finer granularity. The negotiation inherent in the tutoring relationship addresses the diagnosis problem. However, the rapid heterogenation of classrooms at all levels of education, 
and the evolving recognition of cultural differences among diverse learners makes this type of diagnosis relevant in face-to-face instruction as well: a problem yet to be solved.

In everyday conversation, diagnosis of the intentions, motives, and knowledge states of the other conversant takes place turn-by-turn. When misunderstanding occurs, a process that both CA and intelligent tutoring literatures refer to as repair can be used (Heritage, 2013; Brown \& VanLehn, 1980). This process is influenced by the perceived role relationship between conversants. Where a subject-matter authority is performing teaching or tutoring, a particular epistemic relation exists between conversants; in peer tutoring or project work, a different social relation requires a different definition of roles and responsibilities. This indicates that an instructional designer may need to inform conversants of their epistemic roles and how to enact them under different conversational regimes.

Learners who want to become self-regulated can do so only if they are aware of, and take responsibility for, their own knowledge processes. Some innovative instructional theories are discussed in later chapters, such as intentional learning (Scardamalia et al, 1987; Bereiter \& Scardamalia, 1989; Ryser et al, 1995), and reciprocal teaching (Brown \& Palincsar, 1989) that put learners more in charge of their own knowledge acquisition through instructional conversations in which they are responsible for taking a leading role.

\subsection{From the Message Construct to Conversational Structures}

It is impractical to design the structures of individual instructional conversations by hand. What a designer can afford to do is to design a messaging system that specifies how consistent message 
structures, including expressive messages and action invitations, can be systematically integrated with conversational structures supplied by a content-agnostic and synthetic conversational theory like CA. In later chapters, it will become apparent that over decades in the literature of many dominant instructional paradigms this is what has been attempted in terms of strategic instructional theories, but without the complementary structural support of a conversational theory.

The remaining chapters of this monograph supply examples of this quest. Chapter 3, "Message Structure, Educational Psychology, and Instructional Technology”, accounts the attempts by programmed instruction, an early computer-based design project and a method of classroom conversation analysis to structure instructional interactions in a systematic way. Our account shows how these early approaches to the analysis and design of conversational interactions identified the existence of the message construct, though without giving it a name.

Chapter 4, "Message Structure and Intelligent Tutoring Systems", describes the growing recognition that increasingly adaptive instruction depended on the development of more competent systems of message analysis. In that account, it is apparent that the foregrounding of instructional strategic concerns forced into the background the need for a formal theory of conversation structure such as CA. Such structures have been implicit in the rule systems of intelligent tutors, but strategic concerns have tended to overshadow conversational structure concerns. 
Chapter 5, "Message Structure, the Learning Sciences, and Social Learning Theory", shows that an equal emphasis on social aspects of an instructional design has led to acknowledgement of the importance of conversational structure being factored into designs on a par with instructional strategy concerns. This represents the most balanced theoretical stage in the historical development of conversational instructional design.

\section{Conclusion}

What has been described to this point is a body of theory from conversational analysis, integrated with the concept of "message" to illustrate: (a) a natural fit between a structured conversation theory and the message construct proposed by the architectural theory of instructional design, and (b) the manner in which the message construct corresponds with the morphological and strategic structures of a conversation theory at a high level of detail. This suggests a method for embedding instructional messages within more adaptive conversational designs, providing a basis for designing messaging systems that push design decisions to a finer level of granularity, while affording efficiencies of design.

Instructional designers for technology-based systems often assign the creation of message content (and at the same time their concrete representation) to talented writers or editors who have been trained in language use, but not in the principled design of conversations. What has been described to this point opens a way for the training of writers in more specialized forms of writing: first creating a system of messages to convey knowledge, values, and emotional tone in a more precise way, and second asking the writers to collaborate with representation designers to 
obtain the most efficient yet expressive enactment of the messages. Rather than writing long narrative passages as has been the too-frequent practice in the past, writers might be more likely to create basic message elements that could be integrated with structures supplied by conversation theory in structured, more adaptive conversational exchanges. Likewise, human instructors used to relying on their highly fluid, built-in conversational systems might find that the habit of conducting a message analysis during preparation affords them an underlying structure to realize their messaging goals more completely.

We have also tried to make the case that the message construct, and conversational structures made up of messages, link high-level goals of the strategy layer with more detailed, finer-grained goals that can guide the design of conversational interactions. This linkage spans from high-level strategic structures (e.g., provide a demonstration, conduct practice exercise) to the lowest level, where individual student responses within adjacency pairs, sequences, and projects provide assessments to support goal negotiation, adaptation, and progress monitoring.

Finally, we have hoped to show that the message construct serves as a kind of common reference for previously isolated design communities: the designer of traditional instruction, the live instructor, the tutor, and the designer of intelligent tutoring systems. It describes a design construct they can use to integrate conversational properties into instruction in a systematic way. 


\section{References}

Bereiter, C. \& Scardamalia, M. (1989). Intentional learning as a goal of instruction. In L.

Resnick (Ed.), Knowing, learning and instruction: Essays in honor of Robert Glaser. Hillsdale, NJ: Lawrence Erlbaum Associates, 361-392.

Brown, A. L. \& Palincsar, A. S. (1989). Guided, cooperative learning and individual knowledge acquisition. In L. B. Resnick (Ed.), Knowing, learning, and instruction: Essays in honor of Robert Glaser. Hillsdale, NJ: Lawrence Erlbaum Associates.

Brown, J. S. \& VanLehn, K. (1980). Repair theory: A generative theory of bugs in procedural skills. Cognitive science, 4, 379-426.

Christianson, S. (1992). The handbook of emotion and memory: Research and theory. Hove, East Sussex, UK: Psychology Press (Taylor \& Francis).

Drew, P. (2013). Turn design. In J. Sidnell and T. Stivers (Eds.), The handbook of conversation analysis. West Sussex, UK: Wiley-Blackwell, 131-149.

Ede, A. (2006). Scripted curriculum: Is it a prescription for success?. Childhood education, 83:1, 29-32, DOI: $10.1080 / 00094056.2006 .10522871$ 
Flores, C. F., Ludlow, J. J., Bell, C. F., Mora, R. M., Winograd, T. A. \& Graves, M. J. (1985). Method and apparatus for structuring and managing human communications by explicitly defining the types of communications permitted between participants. Patent no. US5208748A. Obtained online 17 January 2020 at: https://patents.google.com/patent/US5208748A/en.

Gunter, P. L. \& Reed, T. M. (1998). Academic instruction of children with emotional and behavioral disorders using scripted lessons. Preventing school failure: Alternative education for children and youth, 42:1, 33-37, DOI: 10.1080/10459889809603166

Heritage, J. (2013). Epistemics in conversation. In J. Sidnell and T. Stivers (Eds.), The handbook of conversation analysis. West Sussex, UK: Wiley-Blackwell, 370-394.

Immordino-Yang, M. H. (2015). Emotions, learning and the brain: Exploring the educational implications of affective neuroscience. New York: W. W. Norton \& Company.

Johnson, W. L. \& Lester, J.C. (2016). Face-to-face interaction with pedagogical agents, Twenty years later. International journal of artificial intelligence in education, 26:25-36.

Johnson, W. L. \& Rickel, J. (1998). Steve: An animated pedagogical agent for procedural training in virtual environments. SIGART Bulletin, 8, 16-21. 
Johnson, W. L., Rickel, J. W. \& Lester, J. C. (2000). Animated pedagogical agents: Face-to-face interaction in interactive learning environments. Journal of artificial intelligence in education, 11, 47-78.

Levinson, S. C. (2013). Action formation and ascription. In J. Sidnell and T. Stivers (Eds.), The handbook of conversation analysis. West Sussex, UK: Wiley-Blackwell, 103-130.

Maynard, D. W. (2013). Everyone and no one to turn to: Intellectual roots and contexts for conversational analysis. In J. Sidnell and T. Stivers (Eds.), Handbook of conversation analysis. West Sussex, UK: Wiley-Blackwell.

Norman, D. A. (2004). Emotional design. New York: Basic Books.

Plavnick, J. B., Marchand-Martella, N. E., Martella, R. C. et al. (2015). A review of explicit and systematic scripted instructional programs for students with autism spectrum disorder. Review journal of autism and developmental disorders, 2, 55-66. https://doi.org/10.1007/s40489-014-0036-3

Rickel, J., \& Johnson, W. L. (1999). Animated agents for procedural training in virtual reality: Perception, cognition, and motor control. Applied artificial intelligence, 13:343-382.

Rogoff, B. (1990). Apprenticeship in thinking: cognitive development in social context. New York: Oxford University Press. 
Ryser, R. G., Beeler, J. E. \& McKenzie, C. M. (1995). Effects of a computer-supported intentional learning environment (CSILE) on students' self-concept, self-regulatory behavior, and critical thinking ability. Journal of educational computing research, 13(4), $375-385$.

Scardamalia, M., Bereiter, C., McLean, R. S., Swallow, J. \& Woodruff, E. (1987). Computer supported intentional learning environments. In A. Collins (Chair), Strategies for teaching thinking skills with interactive technologies. Symposium conducted at the meeting of the American Educational Research Association, Washington, DC. (ED 288913) Downloaded from: https://files.eric.ed.gov/fulltext/ED288913.pdf .

Schegloff, E. A (2007). Sequence organization in interaction: A primer in conversation analysis. Cambridge, UK: Cambridge University Press.

Sidnell, J. (2016). Conversation analysis. Oxford research encyclopedias: Linguistics. Retrieved from: http://linguistics.oxfordre.com/view/10.1093/acrefore/9780199384655.001.0001/acrefore -9780199384655-e-40 . DOI: 10.1093/acrefore/9780199384655.013.40 .

Siegel, D. J. (1999). The developing mind: Toward a neurobiology of interpersonal experience. New York: The Guilford Press. 
Stanton, A. \& Reardon, J. (2008). WALL-E. Burbank, CA: Pixar Animation Studio and Walt Disney Pictures. (Script-to-screen video can be found at: http://www.youtube.com/watch?v=yTkenVTYyic ).

Vygotsky, L. S. (1978). Mind in society: The development of higher psychological processes. (M. Cole, V. John-Steiner, S. Schribner, \& E. Souberman (Eds. and Trans.). Cambridge, MA: Harvard University Press.

Winograd, T. \& Flores, F. (1986). Understanding computers and cognition: New foundation for design. Norwood, NJ: Ablex. 


\section{Chapter 3}

\section{Message Structure, Educational Psychology, and Instructional Technology}

\subsection{The Bridge from Strategy to Conversation}

In this chapter we begin to explore the body of historical evidence for the claim that the message construct is, and has long been, an important design construct, essential to the design of conversational interactions. We have proposed that the message construct is an atomistic structural element of instructional strategy and that it corresponds with the dialogical structures of a conversation theory, as described in Chapter 2. Lacking this type of construct, design theorists have been unable to describe how to bridge the gap between high-level strategic goals and low-level conversational elements.

In this chapter and the ones that follow we review the historical development of interaction design across decades of shifting paradigms of learning and instruction to demonstrate that the missing common denominator has been a basic structure for bridging strategic intent with interactive, more conversational, structures - the intended message. Our historical review has examined literature from many different fields related to education: inventories of classroom expressions; research on partitioning and refinement of instructional strategies; the study of conversational interactions with tutors; inquiry into theoretical principles of learning; and the study of conversation structures and metacognitive learning in social settings.

In this chapter we present three case studies from the period of the 1970s: Markle's work on frame definition for programmed instruction; Merrill's work on Component Display Theory; and 
the work of Smith and Meux on the analysis of classroom discourse. These represent early attempts to deal with an unnamed entity that we define as the message element in a systematic way. In addition, by examining work from both technology-based instruction and research in classroom settings, we are able to show that the interests of the technology-based designer and the classroom instructor merge at this most basic level of design.

\subsection{Programmed Instruction and Message Structures}

The origins of Programmed Instruction (PI) lie in the mid- $20^{\text {th }}$ century. PI is often referred to as a single topic, although a variety of approaches fall under this heading (Skinner, 1954; Crowder, 1960; Lumsdaine \& Glaser, 1960; McDonald et al, 2005).

The basic structure of PI programs is the frame: a packet of information and/or questions sequenced strategically to engage the learner actively. In principle, each frame requires a response from the learner, either overt or covert, so that frames and responses to them constitute a type of conversation. Individual frames could be evaluated for their communication value and their contribution to learning. They can be adjusted in terms of step size, and they can be included into or excluded from a program if tryout data shows them to be of low value. A frame and the learner's response are equivalent to the adjacency pair structure described in conversation theory (see Chapter 2).

Lockee et al (2004) identifies two leading innovators in the programmed instruction movement.

The first, B. F. Skinner, conducted extensive research involving teaching machines at Harvard University beginning in the early 1950s. Skinner's programs were linear and sequenced in a 
fixed order, with the response to one frame leading to the next frame. In latter part of the 1950s a second innovator, Norman Crowder, conducted learning experiments for the U. S. Air Force. His style of frame resembled multiple choice test items, with different selections leading to different destinations, creating a branching structure.

Crowder and Skinner adopted different styles of frame, but the general structure of their frames was similar. Each frame normally had a presentation element comprising a sentence or paragraph (the information element), followed by either a multiple-choice question with multiple responses to choose from, or a request for a constructed response, which would range from a single word to a short paragraph. Consider this paragraph typical of a Skinnerian-style program on stimulusresponse theory (fashioned after Holland and Skinner, 1961):
Anything that follows a behavior and increases the frequency of a behavior is a reinforcer, and anything that decreases the frequency of a behavior is a punisher. For example, when a pigeon presses a lever given the proper stimulus, it is allowed to have a food pellet. If in the future, when the pigeon is given the stimulus it readily approaches the lever and starts to press it, we say that the food pellet is functioning as a

This large paragraph performs several conversational actions. It can be decomposed into atomistic elements, each of which performs a distinct conversational action, as shown in Table 1. Notice the degree to which the action of each message incites a subtle anticipation for the next message and its action. This lends a forward momentum to the utterance and facilitates the 
almost-instantaneous response that normally occurs during conversations, by narrowing the range of possible interpretations.

Table 1. Analysis of a typical Skinnerian programmed instruction frame using conversational analysis, showing message elements within the frame and their corresponding conversational actions (compare with Table 2, Chapter 2).

\begin{tabular}{|l|l|}
\hline \multicolumn{1}{|c|}{ Message } & \multicolumn{1}{|c|}{ Intended action } \\
\hline $\begin{array}{l}<\text { Anything that follows a behavior and increases } \\
\text { the frequency of a behavior is a reinforcer... }>\end{array}$ & $\begin{array}{l}\text { Assertion. Action is fact presentation. No } \\
\text { anticipation markers. }\end{array}$ \\
\hline$<\ldots$ and ... $>$ & $\begin{array}{l}\text { Logical connector. Anticipation is set-up that the } \\
\text { next action may parallel that of the first message. }\end{array}$ \\
\hline $\begin{array}{l}<\ldots \text { anything that decreases the frequency of a } \\
\text { behavior is a punisher. }>\end{array}$ & $\begin{array}{l}\text { Assertion. Narrows the range of possible actions } \\
\text { likely to follow. }\end{array}$ \\
\hline$<$ For example,... $>$ & $\begin{array}{l}\text { Anticipation marker. Much narrower range of } \\
\text { conversation actions may follow. Interpretation } \\
\text { task for learner becomes structure-matching. }\end{array}$ \\
\hline $\begin{array}{l}<\ldots \text { when a pigeon presses a lever given the } \\
\text { proper stimulus, it is allowed to have a food } \\
\text { pellet. }>\end{array}$ & $\begin{array}{l}\text { Structure-matching hypothetical \#1. No clue } \\
\text { about nature of learner action to be required (e.g., } \\
\text { "remember this" vs. "respond"). }\end{array}$ \\
\hline $\begin{array}{l}<\text { If in the future, when the pigeon is given the } \\
\text { stimulus it readily approaches the lever and } \\
\text { starts to press it,... }>\end{array}$ & $\begin{array}{l}\text { Structure-matching hypothetical \#2. No clue } \\
\text { about nature of learner action to be required (e.g., } \\
\text { "remember this" vs. "respond"). }\end{array}$ \\
\hline $\begin{array}{l}<\ldots \text { we say that the food pellet is functioning } \\
\text { as a ... }>\end{array}$ & $\begin{array}{l}\text { Response stem. Type of learner action required is } \\
\text { confirmed. Learner must respond. }\end{array}$ \\
\hline$<\ldots$ & $\begin{array}{l}\text { 1. Specific request for response. } \\
\text { 2. Designation of response type and point of } \\
\text { responding. }\end{array}$ \\
\hline
\end{tabular}

The frame's paragraph is decomposed into multiple message-action units. To borrow a metaphor from Chemistry, the frame's paragraph represents a conversational compound, of which the individual messages are atomic constituents. Message elements bridge the gap between low-level instructional strategy structures and basic structural units of conversation theory.

\subsubsection{The Indeterminate Nature of Actions}

The entries in the intended actions column of Table 1 are not taken from an authoritative list of actions, because such a list does not exist (Levinson, 2013). Conversational actions can be 
obvious or very subtle and limited. Actions are a kind of personally-held knowledge that grows with experience and maturity. This explains why a six-year old still learning the actions of adult conversation can be teased by what a playful adult might guilefully say. As we mature, we are not so easily fooled because we possess knowledge of a wider range of conversational actions. We learn to interpret the intentions and meanings of others by engaging in conversations.

We supplied our own interpretations for the Actions column of Table 1. How can we know if we were right? This question begs a broader one; how can anyone ever know in a conversation that they have correctly understood what the other was intending to communicate? Only further context provided by additional conversational exchanges can confirm interpretational hypotheses. Our own guesses in the table were our attempt to interpret from the context of our own experience what might have been the intentions of the writer, just as context clarifies for the six-year old what we really intend when we are teasing.

The actions intended by exchanges during a conversation are always indeterminate at first, subject to our own confirmation that we have understood the meaning and intention of what was said. In instructional conversations, we deliberately create calculated imbalances in understanding, one of the purposes of which is to help learners achieve finer and finer distinctions between different conversational actions, better equipping them to decode future communications, their meanings, and their intentions. We should expect that we and the learner will always be learning new and more nuanced conversational actions from each other, from an unending list of possible actions. This is the basis for growing understanding that constantly improves us as conversants and makes us capable of profiting even more from future 
interactions. This kind of learning and course correction takes place across multiple exchanges in a process called Repair that was mentioned in Chapter 2 and is elaborated in Chapter 6.

\subsubsection{Actions and Understanding in a Conversation}

Intended actions of utterances are interpreted by receivers when those receivers apply patterns of actions accumulated through experience. This sheds light on how conversants make sense to each other, and what might be wrong when there is a breakdown in understanding. Using stored experience patterns for the purpose of understanding actions in a conversation closely parallels the description of the understanding process as pattern-matching given by Schank in Chapter 2 of Inside Case-based Explanation Schank (Schank et al,1994, Chapter 2).

We propose that the message construct, combined with the concepts of conversation theory, offer designers a tool that is both synthetic (as in designing message systems) and analytic (as in analyzing existing messaging systems), providing a new framework for research in instructional message design and ultimately instructional theory.

The message construct affords designers the ability to: (a) examine their own personal practice of instructional messaging, (b) create a personal theory of instructional messaging, (c) use instructional theory from the literature to inform message decisions, and (d) improve a personal theory of messaging from the examination of existing instructional artifacts. All of these uses of the message construct can be seen among the examples reviewed in this monograph. The examples cited in this and the following chapters are explorations of messaging theories held by designers either explicitly or implicitly. 


\subsubsection{Markle's Application of Message Discipline}

One of the best-known proponents of Skinner's programming approach was Susan Meyer Markle. A student and co-researcher with Skinner, Markle explored the dimensions of frame and message structure trying to formulate prescriptive principles. Her work culminated in a book written in program form titled, Good Frames and Bad: A Grammar of Frame Writing (1964, 1969). Markle's theory of messaging comes close to addressing message design explicitly, without naming the message entity.

The frame concept evolved over time. Early on, because programs had to be structured to fit the constraints of teaching machine delivery, the ideal program was composed of short frames consisting of combinations of information elements, questions, answer prompts, and correct answer reveals, which were obscured from the learner until an answer had been given. An excellent example of a programmed text of this type is Holland and Skinner's, The Analysis of Behavior: A Program for Self-Instruction (1961).

Markle defended her use of the word "grammar" in the subtitle of her book, A Grammar of Frame Writing:

This book is called a grammar because it tries to do what a grammar of language would do. It contains a classification scheme of the basic elements (or structures) and operations (or procedures) and a survey of the possible ways of combining these elements and operations into "good" forms. As with 
many grammars, you could also expect considerable practice aimed at eliminating from your repertoire certain inelegant or unpermitted ways of combining the elements and operations (p. 56).

The variety of "grammatical" structures that could be incorporated into in a Markle program was more complex and nuanced than most design students today realize. There were many subtle ways a frame could be configured with messages and then placed in sequences, both as individual frames and groups of frames working together for a strategic effect. Many of her numerous structuring and sequencing principles are strikingly parallel to those of conversation theory. In Markle's own words, “classifying different frames as being this type or that type could become an academic exercise" (p. 56). We take this as an indication that the real focus of her book was within-frame elements (messages and their actions, in our estimation) and the variety of frame types that could be created through combination.

Three levels of strategic organization of frames are implied in Markle's 1969 book, two of which correspond with structural elements named in conversation theory:

- Single-frame and contiguous-frame arrangements (what CA would term turns, adjacency pairs, and sequences). ${ }^{1}$

- Larger, often non-contiguous frame sequences (what CA would term projects, which are composed of sequences).

\footnotetext{
${ }^{1}$ The level of rigorous analysis to which Markle subjects single frames bears out this observation. See Markle, 1969, Chapter 2, Frame \#11. In this frame, the topic of which is prompts, four varieties of prompting messages are provided in an exploded view, as it were, of a single frame's contents. There are many other types of prompting message, including review, sequence, multiple choices, and visual prompts.
} 
- Sequences of frames using semantically-defined strategy elements to organize subjectmatter within and between frames.

Single-frame and contiguous-frame arrangements. Even though Markle's title refers to frames, her book is really about the structural contents of frames, which we equate with messages and their intended actions. Markle defines many structural elements from which frames are composed, which she describes in message terms. Examples include: prime, stimulus presentation, prompt, response type, feedback, and terminal.

One within-frame structure that Markle does not name, but which she uses extensively in her book is the direct didactic. Direct didactics fall under the heading of "presentations of information." These consist in most cases of extended explanations. Markle's direct didactics are long, sometimes filling half to three-quarters of a page. Reverse engineering of her explanations shows that they contain several kinds of message element, including examples, demonstrations, and exposition of Skinnerian theory.

Strategic multi-frame strategic arrangements. Markle describes multi-frame, multi-message sequences employed to achieve pre-testing, shaping, behavior approximation, feedback, and branching for adaptivity to the individual. She also describes periodic, recurrent messages for review purposes. These frame structures need not be contiguous. Markle's multi-frame strategic sequences correspond with the sequence and project constructs of conversation analysis. 
Sequences of frames organized semantically by subject-matter structures. Markle identifies sequences of frames defined by semantic frame-to-frame relationships: the RULEG system, and mathetics. These fall under the heading of what Markle describes as the "orderly development of the subject matter" (1964, p. 36). They are, in fact, forms defined independent of specific subject-matter that rely on semantic relationships existing within virtually all subject-matters.

RULEG. Markle proposes the use of the RULEG system described by Evans, Glaser and Homme (Evans et al, 1960,1962) as a means of relating message elements, and frames directly to each other. The RULEG system defines frames using semantic relationships inherent in subject-matter structure. A RUL is a general statement, and an EG is an instantiation of the RUL. If the RUL expresses the definition of an oxidation reaction in chemistry, then a set of EGs could be generated containing examples of oxidation reactions.

Mathetics. Mathetics is a message sequencing technique in which the order of behavior chain development is reversed so that instruction starts at the end of the chain then moves forward in the chain until the complete behavior is learned. Heavy priming and cuing of learner responses occurs along the way. For example, teaching a child to tie shoes may begin with the adult performing every step of the action except the last one - pulling the bow tight—-which the child performs. Once that behavior is established, the adult performs all but the last two steps of the chain, which the child performs. This incremental advancement, in reverse, toward full performance continues until children are tying shoes by themselves. 


\subsubsection{Markle and the Message Construct}

The putative topic of Markle's book was frames and frame sequences, but her discussions focus on structures at the sub-frame, or message, level. "Good frames and bad" to her were defined by parts of frames, not frames entire, and she was specific that there were many kinds of message that could be combined into frames. She clearly had in mind atomistic units, and she clearly envisioned their use in automated tutoring systems. In her words:

What are the limits of practicality in creating different programs for different students? At some point we approach the dream state of a private tutor for each student (Markle, 1969, p. 232).

Working within the confines of the S-R theory and the heavy constraints of the delivery medium of her times, and forward-thinking beyond her time, Markle would probably be surprised how relevant her ideas were in today's technological environment.

\subsection{Formalized Instructional Strategy: Gagné}

Contemporary with Markle's work on programmed instruction, Robert Gagné published four editions of The Conditions of Learning (Gagné ,1965, 1970, 1977, 1985), a book that became a major influence with educators and educational technologists. The series made two main contributions: (a) establishing the concept of research-based categories of learning, and (b) linking each category to strategic guidelines that Gagné considered most effective for each category. This concept of linking objective types with instructional moves was a very current 
topic and had been since Ralph Tyler, Bloom's mentor, had popularized the idea in The Basic Principles of Curriculum and Instruction (Tyler, 1949).

The details of Gagné's categories of learning and their associated strategies changed over time as the influence of behaviorist theory featured the first edition of his book evolved into an information processing/cognitivist influence in the fourth. What remained consistent across all editions was grounding of learning categories in the most current research literature. Gagné's strategy prescriptions were expressed at a high level and never reached the analytical level of defining messages. However, the next section describes how Merrill, greatly influenced by Gagné's ideas, took that next step.

\subsection{Component Display Theory: Merrill and TICCIT}

M. David Merrill saw the value of the strategy categories ideas of Gagné, the frame idea from programmed instruction, and the RULEG message structuring ideas of Evans, Glaser and Homme $(1960,1962)$. He combined these conceptual tools with his own research on concept instruction to explore the impact of message structure on how learners form correct and incorrect concepts (Merrill \& Tennyson, 1978). The opportunity to explore these ideas creatively came in the early 1970s with an NSF research grant to C. Victor Bunderson, Merrill's friend and colleague, for the design and development of a TICCIT (Time-shared Computer Controlled Information/Instructional System) instructional system (Bunderson, 1974; Merrill et al, 1980).

Merrill's contribution became to define the instructional delivery component of the system, which had to be learner-, not system-, controlled. This was an ambitious task at the time, given 
the state of computer technology and instructional theory development. Multiple accounts describe in detail the instructional design innovations that emerged from that project (Merrill et al, 1980; Bunderson, 2008; Gibbons \& O’Neal, 2014).

Three key breakthroughs led to solving the learner control design problem:

- Merrill extended Gagné's standard objective types by crossing a content dimension with the behavior dimension and modifying the behavior categories

- He defined instructional strategy formulas for each objective type

- Using the strategy formulas, he applied a logical principle to define a disciplined display typology for the creation of conversational interactions

The system of disciplined display types became the basis for Merrill's component display theory (Merrill et al, 1980; Merrill, 1983), which was the basis for a later component design theory (Merrill, 1987) and later a transaction theory (Merrill, Jones \& Li, 1992). At the heart of it all was a system for the deployment of messages to facilitate conversationality. A message construct was not cited as an underlying structure because Merrill's system was based on logical manipulations of categories rather than a foundation of learning research.

To solve the learner control problem, Merrill devised a set of standard display types reminiscent of the RULEG system, but more evolved, detailed, and disciplined. He defined a core of primary strategy elements, called primary presentation forms, defined by crossing the dimensions of content mode (Generality, Instance) with presentation mode (Expository, Inquisitory). This 
resulted in the matrix in Table 2. The notations for the resulting display types (EG, Eeg, IG, and Ieg) are reminiscent of the RULEG system notations (Evans et al, 1960, 1962).

Generality displays included the expression of a general but defining idea - a rule, a definition, a principle statement, or a fact — or a request for the generality to be expressed by the learner in some way. An expository generality display, then, might give the definition of the dicotyledon category of plants, the formula for calculating acceleration of a falling body, or the steps in a procedure for tying a fishing knot. An expository instance in each of these cases might provide an example of a dicotyledon plant, the calculation of acceleration for a given falling body at a specific time, or a demonstration of one step in the tying of a fishing knot respectively. An inquisitory generality for these same topics might include asking the learner to state the definition of the dicotyledon category of plants, express the formula for calculating falling acceleration, or name the steps in tying a fishing knot. An inquisitory instance for these topics might include presenting a plant description and asking that it be classified as monocot or dicot, asking the learner to calculate falling acceleration at a given point, or asking the learner to tie a fishing knot. 
Table 2. Merrill's primary presentation forms - a core set of display types created by crossing content mode (generality, instance) and presentation mode (expository, inquisitory). In retrospect, it can be seen that each display type represented a category of message within the context of an instructional conversation.

\begin{tabular}{|c|c|c|}
\hline \multirow{2}{*}{ Generality } & Expository & Inquisitory \\
\hline & $\begin{array}{l}\text { Expository } \\
\text { Generality } \\
\text { Presentation of } \\
\text { a generality } \\
\text { (EG) }\end{array}$ & $\begin{array}{c}\text { Inquisitory } \\
\text { Generality } \\
\text { Request for } \\
\text { the generality } \\
\text { (IG) }\end{array}$ \\
\hline Instance & $\begin{array}{c}\text { Expository } \\
\text { Instance } \\
\text { Presentation of } \\
\text { an instance } \\
\text { (Eeg) }\end{array}$ & $\begin{array}{l}\text { Inquisitory } \\
\text { Instance } \\
\text { Request for a } \\
\text { response } \\
\text { (Ieg) }\end{array}$ \\
\hline
\end{tabular}

The message unit was a tacit but never explicit part of design team discussions; the focus was always kept on the predefined display categories defined by component display theory. It soon became apparent that the small computer display surface imposed a severe limitation on the amount of information that could be shown to the learner at any given time. It also became apparent that after the first portion of a strategic (component display theory) display appeared on the computer screen, there might be additional information and interactions with the display that would change only parts of the computer display while leaving some portions unchanged.

Display designs needed to become more dynamic, with changeable parts in order to fit on the screen the necessary information and graphics. Today, we might think of that in terms of display pop-ups or overlays, but TICCIT took place a decade before Windows and Macintosh introduced these display concepts. 
Selectively changing only portions of the screen challenged programmers using the available technology because the volume of display data to be entered would make hand entry prohibitive. Lesson designers also realized that the design of individual displays was time-prohibitive. The solution of this problem came not in the form of a messaging theory but in the form of a computer programming innovation called the "base frame." The designers were shown how to design displays according to a limited set of templates - a type of unfolding, interactive Programmed Instruction frame (focusing on the display type), that drew its form from the component display theory. In fact, the concept of dynamic subject-matter display progressions (as defined by component display theory) through a dynamically-changing computer display (in response to the display size design constraint) relied upon the unfolding of a series of messages inherent in each display type, though the design team did not fully recognize the implications of this.

To aid with the refinement of objective-related strategies, Reigeluth and Merrill proposed an elaboration theory that supplied a unifying principle for the definition of subject-matter structures for the different instructional objective types (Reigeluth, Merrill \& Bunderson, 1978; Reigeluth, 1979; Reigeluth, Merrill, Wilson \& Spiller, 1980). A growing lexicon of presentation forms and strategy standards became useful to designers, subject-matter experts, and computer programmers, constituting a shared design language that made the production of an unprecedented volume of instruction to be produced in a very short time.

Reigeluth wrote about strategic subject-matter structures in terms of their internal semantic relationships after the conclusion of the TICCIT project: 
Our work in instructional strategies has led us to the conclusion that "structural" strategies such as synthesizers (i.e., explicit descriptions of types of pervasive relations among subject-matter components) can have a far greater impact on instructional outcomes than the vast majority of instructional strategy variables that have been investigated to date. (Reigeluth et al, 1978, p. 107)

Reigeluth found that hierarchical task analysis and semantic network analysis were not adequate for the analysis of subject-matter structures that could be used strategically "for the purpose of selecting, sequencing, or synthesizing the subject-matter components" (p. 108).

He defined areas of subject-matter structure within which internal semantic relationships could be arranged hierarchically. He identified new types of hierarchy that could be used by designers to characterize subject-matter structures in a systematic, logical way (e.g., learning-prerequisite, procedural, ordinate, causal). The details of the analyses Reigeluth proposed are not as important as the fact that their end product was a set of message elements defined through a logical, analytic process.

We believe that the classification of constructs (along with a classification of levels of behavior desired for each construct) will be useful for prescribing what we refer to as presentation strategies (which are strategies for the teaching of a single construct) such as the use of attribute isolation, mnemonics, 
divergent examples, and different representation forms.... We also believe that the classification of structures will be useful for prescribing what we refer to as structural strategies (which are strategies for selecting, sequencing, synthesizing, and summarizing related constructs), such as overviews and advance organizers. (p. 124)

Reigeluth's analysis led in the direction of, but stopped short of, identifying the message construct as a basic strategy design atom. In 1987, Merrill described a new component design theory (replacing the old component display theory) that assimilated Reigeluth's elaboration theory (Merrill, 1987). This may be seen as part of his continuing quest to discover elements of instructional strategy through the kind of principled analysis that was accelerated by the TICCIT project. The message construct was an implied next step that becomes apparent now, in a new theoretical and technological environment.

The work of Merrill, Reigeluth, Bunderson, and the TICCIT design team brought together multiple threads, including structural and strategic concepts to create a system that is still in use, in an updated form. With unique combination of ideas and a technological mechanism, it reflected Markle's idea of the adaptive book and foreshadowed the role of message design in intelligent tutors that would be based on different mechanisms but with the same vision of responsiveness to the learner.

\subsection{Smith \& Meux: The Logic and Strategies of Teaching in Education}

Smith and Meux $(1967,1970)$ conducted analyses of classroom discourse "to ascertain some of 
the logical operations involved in teaching." Their analysis took them eventually to the message level, which they described as being "tactical":

The procedural means [of instruction] have two aspects: large-scale maneuvers which we call strategies, and smaller movements, constituting tactical elements of strategies, which we call logical operations (Smith et al, 1967, p. 1).

Smith and Meux define a high-level construct called an "episode", a short conversational exchange equivalent to what CA would typify as a multi-turn sequence. Their list of high-level episodes includes strategic blocks for defining, describing, designating, classifying, comparingcontrasting, conditional inferring, explaining, evaluating, and opining. Within each strategic episode, Smith and Meux identify multiple sub-types, representing what we construe as message types, or message actions, in conversation theory terms.

The "explaining" class of episodes defined by Smith and Meux and its constituent message types are of special interest. These represent messages that might be provided to answer the question “why?". Smith and Meux name eight kinds of message they detected in their analysis for answering "why?". These define the message in terms of the context of intentions a learner might have had for asking the question in the first place:

Normative explaining. Explaining based on how things have been defined in a standard.

"Because the constitution assigns the making of laws to Congress" 
Empirical-subsumptive explaining. Explaining based on empirical evidence.

"Because the solution always turns red when the pH reaches a certain point"

Judgmental explaining. Explaining based on preponderance of opinion.

"Because the majority of people accept that the world is round"

Procedural explaining. Explanation based on application of a procedure.

"Because you have to multiply both sides of the equation by the same value"

Sequent explaining. Explaining based on a chronological ordering.

"Because prophase always occurs before metaphase during cell division"

Teleological explaining. Explaining based on a projected future outcome.

"Because if we want interest to accrue, we must invest some principle"

Explanation by consequence. Explanation based on necessary consequences.

"Because the blood flow to the heart muscle was cut off"

Mechanical explaining. Explanation based on workings of structures.

"Because when the pillar was removed, there was nothing supporting the roof"

Smith and Meux describe the goal of classifying episode types as:

[Working] out procedures and materials to bridge the gap between the theory and the practice.... We must first identify and describe the dimensions of teaching behavior before we can think realistically about concepts and principles relevant to its control. (Smith \& Meux, 1970, p. 1) 
Smith and Meux identify a boundary between high-level blocks of strategic intention (like those formed within the strategy layer) and more-fragmented message types:

'Strategy' refers to a pattern of acts that serve to attain certain outcomes and to guard against certain others. Among the general objectives toward which a strategy may be directed are the following: to ensure that certain learnings will be acquired in as brief a time as possible; to induce students to engage in an exchange of ideas; and to minimize the number of wrong responses as the student attempts to learn concepts and principles.... By 'logical operations' [in our interpretation, messages subsumed within episode types], which are the focus of our study, we mean the forms which verbal behavior takes as the teacher shapes the subject matter in the course of instruction. For example, the teacher reduces concepts to linguistic patterns called definitions; he (sic) fills in gaps between the student's experience and some new phenomenon by facts and generalizations related in a verbal pattern referred to as explanation (Smith \& Meux, 1970, p. 3).

The list of episodes and message types in the 1970 version of Smith and Meux's work is extensive and makes very fine distinctions. These distinctions constitute a natural history of classroom conversational behavior, and they provide the designer of conversational events with a rich vocabulary of highly-granular terms representing messaging actions.

An even more detailed insight into how Smith and Meux bridge high-level strategy with message-level analysis is provided in their 1967 report titled, A Study of the Strategies of 
Teaching (Smith et al, 1967). Strategies is an earlier, formative work based on five years of data collection and analysis of classroom conversational episodes. It refers to the "verbal activities" used during instruction:

Each venture [episode] contains certain verbal activities that are to be understood as ways of obtaining the venture's objective. One of the problems we face in making an analysis of teaching behavior is that of how to conceive of these activities (Smith et al, 1967, p. 46).

The verbal activities they speak of can be equated with messages in most cases. The best example of analysis at the message level is given in reference to what they term the conceptual venture/episode type. Seventeen message types are identified in connection with this kind of episode:

1. A characteristic or quality the referent has.

2. A part the referent has.

3. A function the referent has.

4. A use that the referent has.

5. A characteristic treatment accorded to the referent.

6. A relationship between the referent and something else.

7. The way in which the referent compares with something else with respect to a single characteristic.

8. A condition which produces or causes the referent. 
9. A characteristic of the way in which the referent grows, develops, or changes.

10. A class of things to which the referent belongs

11. An instance or sub-class that the concept has.

12. The results of some operation or procedure involving the referent.

13. A relationship between two or more characteristics of the referent.

14. A characteristic of the variables on which the referent depends.

15. The emotive or persuasive force which the term for the referent has.

16. The alternative ways in which the term for the referent may be used.

17. The difference between one use or meaning of the term for the referent, and some other use or meaning it may have. (Smith \& Meux, 1967, p. 61)

The Smith and Meux analysis focuses on minute design structures at the level of messages. It can be compared with the work of Reigeluth and Merrill on elaboration theory. Whereas Reigeluth and Merrill's method proceeds top-down through analysis to the message level, the research of

Smith and Meux begins at the bottom — the level of everyday message application—and works its way up. Both cases converge toward, and we feel add validation to, the concept of message layer design.

\subsection{Conclusion}

The systems reviewed in this chapter were based on classroom analysis (Smith \& Meux), behaviorist principles (Markle), and principled invention (Merrill, Reigeluth). In the next chapter we transition to a selective review of the message construct as it developed in intelligent tutoring 
systems. We find it interesting that in an advanced technology like ITS, the message construct is a central, but still undefined, design construct, little unstudied in its own right. Despite the change in scholarly context from the 1970 s to the 1980 s, we see that the message construct surfaces as a stable and essential element of instructional designs.

\section{References}

Bunderson, C. V. (1974). The design and production of learner-controlled courseware for the TICCIT system: A progress report. International journal of man-machine studies, 6(4), 479491.

Bunderson, C. V. (2008). Reflections on TICCIT. In M. Allen (Ed.), Michael Allen's e-Learning Annual, 2008. San Francisco, CA: Pfeiffer, 1-30.

Crowder, N. A. (1960). Automatic tutoring by intrinsic programming. In A. A. Lumsdaine and R. Glaser (Eds.), Teaching machines and programmed learning. Washington, DC: National Education Association, 286-298.

Evans, J. L., Glaser, R. \& Homme, L. E. (1960). The RULEG system for the construction of programmed verbal learning sequences. Washington, D. C.: United States Department of Health, Education, and Welfare. Report CRF-691-3. ED 014894. 
Evans, J. L., Homme, L. E. \& Glaser, R. (1962). The RULEG system for the construction of programmed verbal learning sequences. Journal of educational research, 55(9), 513-518.

Gagné, R. M. (Ed.)(1965). Psychological principles in system development. New York: Holt Rinehart \& Winston.

Gagné, R. M. (1968). Learning hierarchies. Educational psychologist, 6, 1-9.

Gagné, R. M. (1977). Types and capabilities of learning hierarchies in instructional design. Journal of instructional development, 1(1), 8-10.

Gagné, R. M. (1985). The conditions of learning, (4th ed.). New York: Holt, Rinehart, and Winston.

Gibbons, A. S. \& O’Neal, A. F. (2014). TICCIT: Building theory for practical purposes. International journal of designs for learning, 5(2), ???-???.

Holland, J. G. \& Skinner, B. F. (1961). The analysis of behavior: A program for self-instruction. Cambridge, MA: Harvard University Press.

Levinson, S. C. (2013). Action formation and ascription. In J. Sidnell and T. Stivers (Eds.), The handbook of conversation analysis. West Sussex, UK: Wiley-Blackwell, 103-130. 
Lockee, B. B., Moore, D. M., \& Burton, J. K. (2004). Foundations of programmed instruction. In Jonassen, D. \& Driscoll, M. (Eds.), Handbook of research on educational communications and technology (2 $\left.2^{\text {nd }} e d.\right)$. New York: Taylor and Francis Group, 545569.

Lumsdaine, A. A., \& Glaser, R. (Eds.). (1960). Teaching machines and programmed learning: A source book. National Education Association.

Markle, S. M. (1964). Good frames and bad: A grammar of frame writing. New York: John Wiley \& Sons.

Markle, S. M. (1969). Good frames and bad: A grammar of frame writing (2 ${ }^{\text {nd }}$ ed.). New York: John Wiley \& Sons.

McDonald, J. K., Yanchar, S. C. \& Osguthorpe, R. T. (2005). Learning from programmed instruction: Examining implications for modern instructional technology. Educational technology research and development, 53(2), 84-98.

Merrill, M.D. (1983). Component Display Theory. In C. Reigeluth (ed.), Instructional-Design Theories and Models: An overview of their status. Hillsdale, NJ: Erlbaum Associates, 397424. 
Merrill, M. D. (1987). The new component design theory: Instructional design for courseware authoring. Instructional science, 16, 19-34. https://doi.org/10.1007/BF00120003

Merrill, M. D., Schneider, E. W. \& Fletcher, K. A. (1980). TICCIT (Instructional Design Library, Vol. 40). Englewood Cliffs, NJ: Educational Technology Publications.

Merrill, M. D., Jones, M. K. \& Li, Z. (1991). Instructional transaction theory: Classes of transactions. Educational technology, 32(6), 12-26. Available at: https://bit.ly/3b2AqTP

Merrill, M. D. \& Tennyson, R. D. (1978). Concept classification and classification errors as a function of relationships between examples and nonexamples. Improving human performance quarterly, 7(4), 351-364.

Reigeluth, C. M. (1979). In search of a better way to organize instruction: The elaboration theory. Journal of instructional development, 2(3), 8-15. EJ222015

Reigeluth, C. M., Merrill, M. D. \& Bunderson, C. V. (1978). The structure of subject-matter content and its instructional design implications. Instructional science, 7, 107-126.

Reigeluth, C. M., Merrill, M. D., Wilson, B. G. \& Spiller, R. T. (1980). The elaboration theory of instruction: A model for sequencing and synthesizing instruction. Instructional science, 9(3), 195-219. 
Schank, R. C., Kass, A. \& Riesbeck, C. K. (1994). Inside case-based explanation. Hillsdale, NJ: Lawrence Erlbaum Associates.

Skinner, B. F. (1954). The science of learning and the art of teaching. Harvard Educational Review, 24, 86-97.

Smith, B. O., Meux, B. O., Coombs, J., Nuthall, G. \& Precians, R. (1967). A study of the strategies of teaching. Urbana, IL: Bureau of Educational Research. ERIC ED 029165.

Smith, B. O. \& Meux, B. O. (1970). A study of the logic of teaching. Urbana, IL: University of Illinois Press.

Tyler, R. W. (1949). Basic principles of curriculum and instruction. Chicago: University of Chicago Press. 


\section{Chapter 4 \\ Intelligent Tutoring Systems \\ and the Inevitability of the Message Construct}

At the third and deepest level of interaction there are dialogue systems aimed at permitting the student to conduct genuine dialogue with the computer (Suppes, 1969, p. 44, emphasis in the original).

\subsection{A New Epoch, and an Old Construct}

New hardware and software concepts matured in the 1960s to open the way for a great variety of new, dynamic instructional forms. Serious and well-funded experimentation in intelligent tutoring systems marked the beginning of a new epoch of exploration. Change was rapid and constant. However, one element of instructional designs, the message construct, remained a stable factor and even moved to the foreground during this period of heated discovery. Because design was taking place at a much more detailed level during this period, there was much greater need for more granular constituents of designs, and messages (and their representations) filled the vacuum.

\subsection{Adaptive Instruction and the Message Construct}

With the increase of research on intelligent tutoring systems (ITS) in the 1960s the message construct and concept of message layer design became more visible. By definition intelligent tutoring systems engage the learner in adaptive conversations using generative mechanisms that, to some extent, assemble resource fragments into artifacts and experiences at the time of instruction. This requires designs that are conceived in much greater detail than was formerly required. 
Intelligent tutoring systems stand in contrast to more traditional technology-based instructional systems in which pre-composed media resources are packaged and stored with fixed delivery logic. Such instructional artifacts may include branching and choice points within that logic, as well as interactive display elements, but these are fixed and planned in advance. Intelligent systems also involve choice points and interactive display elements, but decisions at choice points generally involve a larger number of variables and momentary situational variables. Displays need not be fixed but may also be assembled in real-time from a library of fine-grained elements or even computed and drawn dynamically, depending on moment-to-moment interactions with the learner. In order for an intelligent tutor to provide instructional responses to the learner, message-creation rules must generate the intent of the responses and representation rules must then assemble and configure the elements that give expression to those intentions.

This chapter is not a deep review of ITS literature; it gives an account of key points in ITS history where the message construct emerged from the background of instructional design topics to become an essential concern in ITS designs.

\subsection{Early Emergence of Message Layer Design in ITS}

ITS designs began at an early stage to lay bare the importance of message structures and messaging mechanisms. Carbonell's SCHOLAR system (1970) deposited data elements supplied from a semantic network (a family of interlinked data bases) into the slots of templated messages to produce text representations like, "Please indicate if the following statement is correct: The $<$ area $>$ of $<$ Paraguay $>$ is $<$ approx 47,432 square miles $>$ " (where angle brackets indicate the slots into which data base terms were substituted). A different template using the same complex data 
base might produce text like: " $<$ Right $>$. The $<$ language $>$ of $<$ Brazil $>$, is $<$ Portuguese $>$ ".

Carbonell's great achievement was generating messages (and their representations) in real time instead of pre-composing messages and storing their representations in advance of their use. In the SCHOLAR system, messages varied to the degree anticipated by designers of the message templates and by the template-filling elements included in the semantic network.

\subsection{Strategic Goals and Messaging Rules}

Allan Collins took up work on SCHOLAR following Carbonell's early death and revised the message and representation-generation mechanism. After studying transcripts of live tutoring sessions, Collins abstracted tutoring rules that were expressed in the form of if-then production rules, which he called "condition-action pairs" (Collins, 1976, 1977). He applied these rules in the generative engine of a new tutoring system named WHY. Different types of WHY rules performed different functions, among them, determining when a message needed to be generated, and determining what would be communicated to the learner.

The example production rule below exemplifies two important aspects of WHY's tutorial actions: (a) recognition of the strategic situation (the "when"), and (b) matching the situation with an appropriate message to the learner (the "what"):

IF (1) a student explains the value of the dependent variable based on one or more factors that are not necessary, or

(2) makes a prediction based on one or more factors that are not necessary, 
THEN (3) ask if it is a general rule that the unnecessary factors must have the values specified, given the value of the dependent variable.

(Collins, 1982, p. 105)

The plain English version of this rule is, "If the student is reaching a decision based on an irrelevant factor or too few factors, ask them (message them) whether they really believe that that factor and only that factor is necessary". Consider this rule being applied to specific subjectmatter. If the instructional goal was for the learner to predict accurately whether rice could be grown in a particular place under certain growing conditions (water, temperature, soil quality, etc.), then the dependent variable would be "the ability to grow rice". The natural language version of the above rule would then be: "If a student (erroneously) asserts that lots of rainfall is sufficient for growing rice in a place, or incorrectly predicts that a place with heavy rainfall will grow rice because of rainfall alone, then form a message to ask "Do you think it is sufficient alone to have heavy rainfall to grow rice?" (Collins, 1982, p 105).

In this rule there is an inherent distinction between: (a) detecting status with respect to a strategic goal (the "if") and (b) specifying a message supposed to help satisfy that goal (the "then"). The word goal must be understood as it is used here. Our reference is not to an instructional goal, but rather, to a momentary strategic goal that a designer (or an instructor) has chosen to fit momentary circumstances. The difference is a matter of ends versus means: an instructional goal is the end, and the strategic goal is a momentary means for moving forward, toward achievement of an instructional goal. Messages, in turn, are means chosen for satisfying the momentary strategic goal. Strategic goals change from moment to moment during instruction; instructional 
goals last until instruction is finished. Adaptive instruction thus consists of messages arranged in sequence dynamically in response to a series of momentary strategic goals determined either by software or a live instructor.

Table 1, taken from Collins (1977), clarifies this distinction among terms with an example. The column on the left lists eight momentary strategic goals that a live or intelligent tutor might select for a given learner at a given moment to move instruction forward during a Socratic dialogue. The rule we used as an example above can be found in Table 1 under the strategic goal "unnecessary factors" and the message "probe for a sufficient factor". Notice that the goals are portable and generic, because they do not refer to a specific subject-matter. For each strategic goal in the left column of Table 1, the column on the right lists multiple messaging options that a system like WHY or a live instructor might choose in pursuit of an immediate strategic goal, taking into account the learner's responses and perceived knowledge state.

Multiple classes of rules are necessary in an intelligent tutor in addition to the kind in this example. Rules that translate the strategic intention into specific message substance are needed; then additional representational rules are required to give representations their substance. In early versions of a tutor, the message intention might be linked directly with a textual representation. However, in later ITS examples, that we will review, the translation of intent into representations is non-trivial. In all of those cases, message formation precedes the design of representation, unless the representation is a fixed resource, in which case, the adaptivity of the tutor is reduced. 
Table 1. High-level message categories in Collins (1977) used to drive the creation of messages in response to high-level strategic goals defined by intelligent tutor rules.

\begin{tabular}{|l|l|}
\hline \multicolumn{1}{|c|}{ Strategic goal } & \multicolumn{1}{c|}{ Potential messaging strategy } \\
\hline Case selection & $\begin{array}{l}\text { Ask about a particular case } \\
\text { Pick a counterexample for an insufficient factor } \\
\text { Pick a counterexample for an unnecessary factor } \\
\text { Pick an example with the same factors }\end{array}$ \\
\hline Ask for factors & $\begin{array}{l}\text { Ask for prior factors } \\
\text { Ask for intermediate factors } \\
\text { Ask for subsequent factors } \\
\text { Ask how the variable depends on a given factor }\end{array}$ \\
\hline Prediction & Ask for a prediction about a particular case \\
\hline Entrapment & $\begin{array}{l}\text { Pose a misleading question } \\
\text { Form a general rule for an insufficient factor } \\
\text { Form a general rule for an unnecessary factor }\end{array}$ \\
\hline $\begin{array}{l}\text { Probe reasoning strategy } \\
\text { and hypothesis testing }\end{array}$ & $\begin{array}{l}\text { Request a test of a hypothesis about a factor } \\
\text { Ask what are the relevant factors to consider? } \\
\text { Test for consistency with a given hypothesis }\end{array}$ \\
\hline Inform student & $\begin{array}{l}\text { Inform the student of a correct fact or relationship } \\
\text { Point out a necessary factor } \\
\text { Point out a sufficient factor }\end{array}$ \\
\hline Insufficient factors & $\begin{array}{l}\text { Form a general rule for an insufficient factor } \\
\text { Pick a counterexample for an insufficient factor } \\
\text { Probe for a necessary factor } \\
\text { Point out a necessary factor } \\
\text { Probe for the similarities between two cases }\end{array}$ \\
\hline Unnecessary factors & $\begin{array}{l}\text { Form a general rule for an unnecessary factor } \\
\text { Pick a counterexample for an unnecessary factor } \\
\text { Probe for a sufficient factor } \\
\text { Point out a sufficient factor } \\
\text { Probe for the differences between two cases }\end{array}$ \\
\hline
\end{tabular}

\subsection{Further Separating Message from Representation}

Later in the 1970s, John R. Anderson began to develop a theory of cognition called ACT-R (Anderson, 1976; Anderson et al, 1996), which continued for many years. In his research lab Anderson designed a succession of intelligent tutors as a tool for evolving and testing the theory. This family of tutoring systems called "cognitive tutors" captured knowledge in the form of production rules, much like Collins'. Anderson's tutors placed strong emphasis on the development of high-order metacognitive skills. The importance of message design to Anderson 
is embodied in his assertion that, "a key feature of a tutor is what it says to the student during a problem-solving episode" (Anderson et al, 1996, p. 30). Anderson tutoring rules differed according to the knowledge domain they taught, so each of his lab's tutors required a fresh set of metacognitive teaching rules, as well as messaging rules. Early cognitive tutor messages were directive in nature. Whereas Collins' WHY rules caused the tutor to ask (or answer) questions in a Socratic dialogue, early cognitive tutors were based on a theory of direct instruction and immediate correction. Several kinds of messages were provided simultaneously to learners, representing multiple strategic intentions that were active at any given time, some administrative, some in support of maintaining orientation to the problem, and some to facilitate responding. Figure 1 shows a multi-window graphical interface from an early version of the LISP tutor. Each window contained a different type message. The subject-specificity of the messages explains Anderson's use of different rule sets for each tutor.

Multiple windows made possible simultaneous messaging representation for multiple threads of a complex instructional conversation. The learner takes initiative within this interface by determining which thread to respond to at a given moment using the programming window. This example indicates how it may be useful to make multiple message types available to the learner at the same time during tutoring: messages that might be administrative, directive, subject-matter related, and supportive of scaffolding functions. 


\begin{tabular}{|c|c|}
\hline Problem & Skill \\
\hline $\begin{array}{l}\text { This space contains a statement of the } \\
\text { problem to be solved. }\end{array}$ & $\begin{array}{l}\text { This space presents a list of skills } \\
\text { being mastered and a ribbon showing } \\
\text { the level of skill that has been } \\
\text { demonstrated in each, from partial to } \\
\text { complete. This list is determined } \\
\text { through highly detailed task analysis } \\
\text { of LISP programming competencies. }\end{array}$ \\
\hline Programming & Menu \\
\hline \multirow[t]{3}{*}{$\begin{array}{l}\text { In this space learners enter elements of a } \\
\text { LISP program. A template of the LISP } \\
\text { function to be completed is displayed, and the } \\
\text { learner adds to it by selecting items from the } \\
\text { Menu window and by typing. }\end{array}$} & $\begin{array}{l}\text { This space provides the learner a searchable } \\
\text { directory of LISP program statement types. }\end{array}$ \\
\hline & LISP Reference \\
\hline & \multirow[t]{3}{*}{$\begin{array}{l}\text { This space provides the learner a reference } \\
\text { document of LISP program structure names, } \\
\text { definitions, and explanations that are used for } \\
\text { instructional presentations, how-to directions, } \\
\text { and modeled examples. }\end{array}$} \\
\hline Hint & \\
\hline $\begin{array}{l}\text { This space contains a hint toward solving the } \\
\text { problem if one is requested. }\end{array}$ & \\
\hline
\end{tabular}

Figure 1. Division of the screen display in an Anderson tutor. This example is abstracted from an early version of the LISP tutor.

\subsection{Message Terminology in ITS Literature}

Discussions in early ITS literature are seldom about message properties, and the message element is not often a focus topic in its own right. Early terminology evolved out of necessity to support more detailed discussions about message typing, functions, purposes, and properties. Existing terminology was sometimes borrowed from programmed instruction literature. Broad terms like "prompt", "hint", and "feedback" were (and still are) used regularly to describe types 
of message, but often without clear definition. Consequently, a "hint" as implemented in one ITS could easily differ from a "hint" implemented in another system. Several studies of messaging have been compiled to provide catalogues of message types without linking them to the strategic circumstances where they might be used (see, for example, Chi et al, 2001, D'Mello, et al, 2010; and Graesser, 1992).

Following a study comparing the activities of human and intelligent tutors, Douglas Merrill and his team (Merrill et al, 1992) compiled an inventory of momentary strategic goals (without associated messages) that under certain conditions might be chosen by tutors during an instructional session. Table 2 shows our adaptation of Merrill's list, which turns out to be a mixture of high-level and mid-level strategic goals whose existence during instruction would most certainly occasion the use of multiple messages in a conversational exchange. Several studies provide catalogues of message types, but without linking them to particular circumstances when they might be used (see, for example, Chi et al, 2001, D'Mello, et al, 2010; and Graesser, 1992). These studies serve as catalogues (similar, perhaps, to swatch books) one might browse to get a higher-level view of the rich variety of conversational messages. 
Table 2. Listing of momentary strategic goals that represent occasions for different kinds of messages and conversational exchanges. These are not organized thematically. Some items may overlap. Adapted from Merrill et al (1992).

\begin{tabular}{|l|l|l|}
\hline Provide immediate r/w & Compare solutions & Set role expectations \\
feedback & Request explanation & Support self-assessment \\
Support exploration & Coach & Prioritize errors \\
Support discovery & Request reflection & Support planning \\
Provide & Request articulation & Report progress \\
correction/Debugging & Set the task & Support reasoning processes \\
Answer learner's question & Negotiate goals & Remedy confusion as it appears \\
Review/replay problem & Promote a sense of challenge & Maximize metacognition \\
solution & Remind/Review & Support recovery from error \\
Request & Question & Confirm correct responses \\
explanation/elaboration & Set tone & Highlight faulty reasoning Supply \\
Guide problem solving & Create anticipation & tools \\
Model performance & Direct attention & Express agreement \\
Provide hint & Provide examples & Compliment \\
Helps & Share control & Provide directions \\
Performed demonstration & Guide self-correction & \\
& Explain & \\
\hline
\end{tabular}

With additional analysis, each of these strategic goals could be decomposed into finer goals, eventually reaching the level of specifying messaging actions. An example of this kind of decomposition was given in Chapter 3, Table 1. The individual message elements in that table each perform a conversational action as shown. Yet collectively they perform a higher-level strategic function that corresponds with the entry in Table 2 above, called "Provide right/wrong feedback". In turn, providing right/wrong feedback might be designed as a component of an even higher-level strategic purpose called "Coach", which is also found in Table 2 above. These examples illustrate the relationship between messaging actions and the hierarchy of strategic purposes they help to satisfy.

Analysis to this level is impractical for the typical instructional designer for every project. However, a designer might abstract master patterns for each of the strategic goals and reuse 
them, for example, one for "Coach", and another for "Provide feedback". A single master pattern for each strategic (not instructional) goal could take into account a number of learner response contingencies in the form of rules and be very flexible in dealing with different learner responses. A pattern would only have to be created once in the abstract, and if it was made subject-matter independent, it could be reused. Such a pattern would of course reflect the instruction-theoretical preferences of its creator, which we expect would in turn reflect a learning-theoretical stance. What we are recommending here are not fixed-logic, reductive structures. Rather, we suggest a catalog of reusable units might exist that can be called into use at a contingent moment to supply structure for conversational exchanges.

The patterns that have been abstracted and applied within ITS systems exhibit this characteristic. Pattern-making has been a practice of ITS developers from the beginning. Collins' WHY rules contain Collins' preference for Socratic teaching methods, and Anderson's cognitive tutor rules embody his preference for direct instructional methods. In Collins' case, one strategy fits all, and only one set of rules is necessary. In Anderson's case, different subject matters require different rule sets, but messaging structures need be built only once, to be abstracted and reused many times. By means of templates of this kind, adaptive conversational interaction patterns can be obtained within ITSs, and also a reduction in designer effort.

\subsection{Messaging and Scaffolding}

During the course of research on live tutoring, Wood, Bruner, and Ross (1976) identified a technique for supporting learning they called "scaffolding." They defined scaffolding as a 
“means whereby an adult or 'expert' helps somebody who is less adult or less expert" during learning (p. 89). For them, scaffolding was:

\begin{abstract}
A kind of...process that enables a child or novice to solve a problem, carry out a task or achieve a goal which would be beyond [their] unassisted efforts. This scaffolding consists essentially of the adult "controlling" those elements of the task that are initially beyond the learner's capacity, thus permitting [them] to concentrate upon and complete only those elements that are within [their] range of competence. The task thus proceeds to a successful conclusion. (p. 90).
\end{abstract}

The concept of scaffolding is relevant to message layer design because scaffolds imply that some form of messaging must occur. The theme of scaffolding in intelligent tutors emerged strongly in the 1990s as a result of influences from the learning sciences and social learning theory. The concept of scaffolding has become popular and predictably broad; it is so often invoked that Pea (2004) observed: "I am perhaps not the only one who feels that the concept of scaffolding has become so broad in its meaning...that it has become unclear in its significance" (p. 423). It is not surprising, then, that the immense body of literature on scaffolding describes a variety of messaging patterns relevant to message layer design.

Scaffolding is used to implement a "proleptic" style of instruction: instruction of a type that assumes that the ability to perform already exists, projecting performance in the future as if the capability were already there. Cole calls this the "cultural mechanism that brings the past into the present" (1996, p. 183). This style of instruction can be indirect and subtle. For example, it can 
be the instructional equivalent of saying, obliquely, "Has anyone seen the salt?", instead of "Please pass the salt." This range and subtlety of messages requires the designer to consider in greater detail nuanced practices of the best human tutors. Scaffolding represents a design requirement that leads to an almost unlimited variety of messages.

In addition to its subtlety, messaging for scaffolding is especially challenging because scaffolding is dynamic_-adjusted to a learner's immediate need, which changes moment-tomoment. Scaffolds, and the messages comprising them, must also "fade" dynamically as the learner becomes capable of acting alone. A message system must be capable of providing support at all points along a student's learning trajectory, remembering the past as a means of adjusting to the future. As Wood cautions, a static scaffolding system risks "creating too much dependency on the tutor" (Wood et al, 1976, p. 98).

Quintana et al (2004) propose a framework of guidelines and strategies for the design of scaffolded experiences in science inquiry. This framework was constructed after an analytic study of the research on ITS and problem-based learning in science and math. It represents an effort to codify a new framework for discussing appropriate kinds of strategy, which we have shown leads to message design. Seven guidelines for "pedagogical support” identified by Quintana are identified in Table 3, along with subdivisions that suggest the first stages of decomposition leading to messaging. 
Table 3. A framework of guidelines and strategies for the design of scaffolding experiences in science inquiry (From Quintana et al, 2004, p. 345).

Guideline 1: Use representations and language that bridge learners' understanding. Strategy 1a. Provide visual conceptual organizers to give access to functionality. Strategy $1 b$. Use descriptions of complex concepts that build on intuitive ideas. Strategy 1c. Embed expert guidance to help learners use and apply science content.

Guideline 2: Organize tools and artifacts around the semantics of the disciplines. Strategy 2a. Make disciplinary strategies explicit in learners' interactions with the tool.

Strategy $2 b$. Make disciplinary strategies explicit in the artifacts learners create.

Guideline 3: Use representations that learners can inspect in different ways to reveal important properties of underlying data.

Strategy 3a. Provide representations that can be inspected to reveal underlying properties of data.

Strategy $3 b$. Enable learners to inspect multiple views of the same object or data. Strategy 3c. Give learners "malleable representations" that allow them to directly manipulate representations.

Guideline 4: Provide structure for complex tasks and functionality. Strategy 4a. Restrict a complex task by setting useful boundaries for learners. Strategy $4 \mathrm{~b}$. Describe complex tasks by using ordered and unordered task decompositions.

Strategy 4c. Constrain the space of activities by using functional modules.

Guideline 5: Embed expert guidance about scientific practices.

Strategy 5a. Embed expert guidance to clarify characteristics of scientific practices.

Strategy $5 b$. Embed expert guidance to indicate the rationales for scientific practices.

Guideline 6: Automatically handle non-salient, routine tasks.

Strategy 6a. Automate non-salient portions of tasks to reduce cognitive demands. Strategy $6 \mathrm{~b}$. Facilitate the organization of work products.

Strategy 6c. Facilitate navigation among tools and activities.

Guideline 7: Facilitate ongoing articulation and reflection during the investigation. Strategy 7a. Provide reminders and guidance to facilitate productive planning. Strategy $7 \mathrm{~b}$. Provide reminders and guidance to facilitate productive monitoring. Strategy $7 \mathrm{c}$. Provide reminders and guidance to facilitate articulation during sense-making.

Strategy $7 \mathrm{~d}$. Highlight epistemic features of scientific practices and products.

\subsection{Non-Textual, Non-verbal Messages}

The ITS examples cited so far have used messages that could be converted, for the most part, into textual or verbal representation forms. Historically, as more sophisticated graphic and audio 
tools have become available, designers seize on them to create more versatile graphical interfaces that offer interactions which text-only interfaces cannot. This trend took root in the strategic plans of ITS designers. Anderson's Geometry cognitive tutor was able to construct unfolding geometric constructions dynamically to support students in selecting the next step of a proof (Anderson et al, 1985). White and Frederiksen built a QUEST tutor that was able to display realistic and dynamic diagrams of electrical circuits flows (White \& Frederiksen, 1990). "How the West Was Won" could display a graphical learning game interface (Burton \& Brown, 1979). SMITHTOWN could display complicated economic data tableaus (Shute \& Glaser, 1990). STEAMER could supply a drag-and-drop graphical interface that allowed learners to connect shipboard boiler components together and run simulated problems on their constructions (Hollan et al, 1984). Behind all of these graphical representations there was strategic intention, and graphical representations were used to convey the messages that were their precursor.

Rickel, Johnson, and Lester (Johnson \& Rickel, 1998; Johnson, Rickel \& Lester, 2000; Johnson \& Lester, 2016) demonstrated the ability to link dynamic images closely with messages in the STEVE intelligent tutoring system. STEVE's purpose is to train operating procedures for ship boilers. Within a virtual reality world, a learner and an automated tutor, STEVE, move about and interact in the 3-dimensional environment representing the control area of the boiler in its shipboard setting. STEVE is an animated agent —a tutor with a visible presence in the learner's head-mounted VR display. STEVE performs tutoring in three modes: tutor-initiative, learnerinitiative, and shared learner-tutor initiative. Tutor initiative mode resembles traditional instructor-led training that includes didactics, demonstrations, and performance challenges to the learner. Students may ask questions at any time and may claim the lead in actions. 
During all modes, the learner is represented by an avatar, and the learner's point of view is over the avatar's shoulder. Importantly, the avatar for STEVE is in constant view, moving about within the 3-D world as necessary to stay in the learner's view. In learner mode, STEVE can answer questions posed through speech by students and give demonstrations of procedures as requested. STEVE can also give auditory explanations, answering "why" questions from the learner.

The feature of STEVE that most clearly demonstrates the bridging of strategy, message, and dynamic graphic content is the deliberate use of gaze and physical gestures to direct and engage the attention of the learner. STEVE looks at the learner during expository delivery; however, at the appropriate moment during a demonstration, STEVE directs his gaze toward a control about to be operated as STEVE names the control, as if to say, "This control is located here". STEVE's graphic hand also moves to the control, a gesture representing the same message. However, once he has indicated the location of the control in this manner, STEVE's gaze returns to the learner, as if to say, "I am addressing you and speaking directly to you". The turn of the hand and the turn of the gaze are all intentional in STEVE. Gestures and gaze are used economically to convey specific messages. A detailed exposition of the gestural (non-verbal) features of STEVE is provided by Rickel and Johnson (1999).

\subsubsection{Graphical message generation in a simulation: STEAMER}

An intelligent instructional system called STEAMER (Hollan et al, 1984) afforded instructional conversations with a dynamic computer model through interactions in a graphical-symbolic 
language. STEAMER afforded learners highly interactive instructional experiences with a steamoperated ship power plant. One of STEAMER's most interesting features was a Feedback MiniLab, a model construction tool featuring: (a) an interactive graphical interface for symbol manipulation and model construction, and (b) the generation of wordless conversational messages through computations of the constructed model. MiniLab provided learner conversations directly with a simulation model just constructed using a graphic, action-centered, non-verbal, and efficient symbolic language.

In the MiniLab, the component parts of a complex shipboard propulsion system were represented graphically in a workspace (see Figure 2). Learners could drag a component symbol into an assembly area, dropping it next to a component they want it to connect with. If two components could connect, they become graphically attached to a growing display of connected parts. As that happened, small programs within each component communicated with the programs of neighboring components: each performing their functions and influencing the values of the other components in the larger assembly.

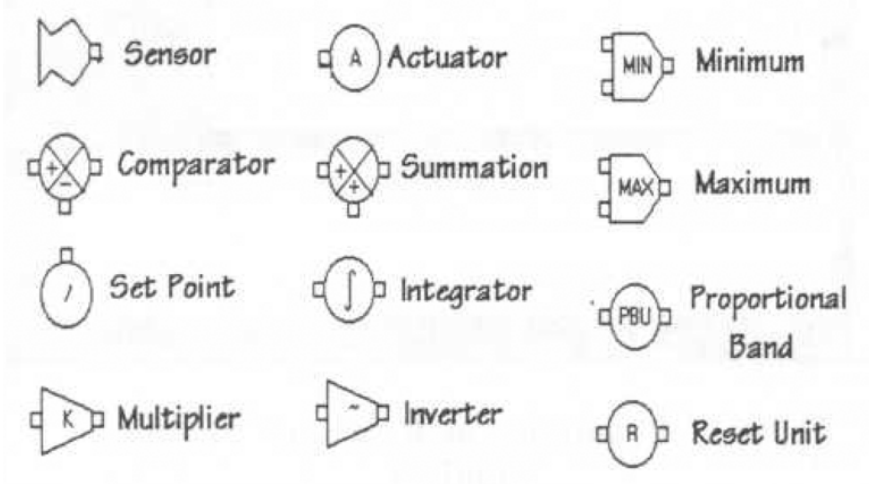

Figure 2. Component schematics for a propulsion unit that learners could assemble into a configuration prior to experimenting with its operation in the Feedback MiniLab (from Forbus, 1993). 
When a sufficient number of components was assembled to make a workable unit (such as a controller, a valve complex, or a metering unit) the assembly could be operated with controls, giving back to the learner a realistic response, including graphical performance diagrams of the unit showing the stabilizing of the response of the assembly over time. Figure 3 shows an assembled unit and a performance curve representing its operational status.
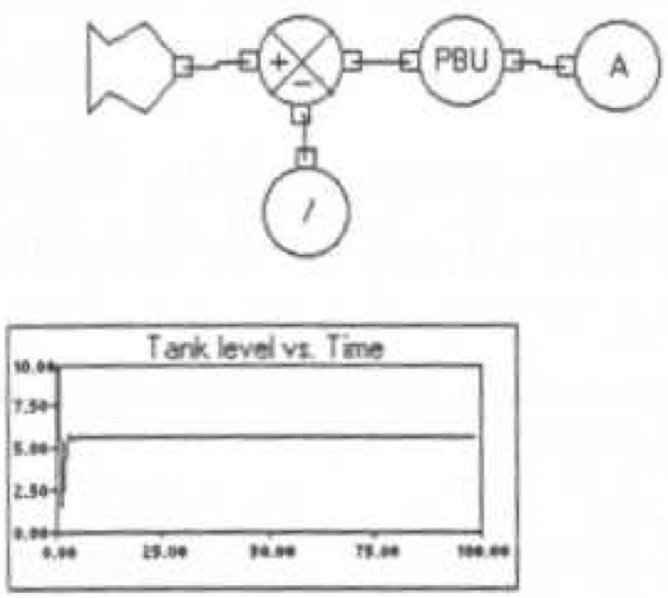

Figure 3. A completed assembly of components that have been connected and tested in the Feedback MiniLab's workspace, showing also the results of a test of the functioning of the assembly (from Forbus, 1993).

By creating assemblies of components, testing them, and then combining them with other assemblies, a learner was, in effect, conducting experiments in a propulsion laboratory. The workspace had no advance knowledge of what the learner would choose to build and test, so everything was generated in a real-time response to learner actions.

The idea of a graphical assembly-and-test interface was new at the time STEAMER was created. Today the concept lives in a variety of forms, including readily-available robotic construction systems, buildable toy systems, and computational block systems used in STEM instruction. For our purpose, all these systems illustrate that the message construct is more than verbal ideas 
waiting to be turned into text. The message construct as applied in these simulated experiences challenges our imaginations to think in terms of the form of the pre-representation message, independent of representational form and based on a dynamic, freshly-computed knowledge source (see Wenger, 1987, Chapter 19).

\subsubsection{Simplifying message generation in a simulation: Dragoon}

One innovative system under development—-the Dragoon system—stresses tutorial capabilities combined with efficient simplicity of model building (VanLehn et al, 2016). Among other things, Dragoon explores new concepts that simplify and economize conversational messaging.

The Dragoon simulation system challenges learners to define models of human-made or natural systems and test them against reality. The goal of the system is to teach the skill of modelbuilding, a key STEM goal. A learner uses a simple symbolic conversational language in Dragoon to construct and tune a system model and then use real data to test the veracity of the model.

Discipline in messaging is maintained by using a limited set of strongly typed message forms:

- Simplified model-building software uses constrained conversational patterns and mostly graphical communication

- A set of abstract problem solving patterns ("schemas") are provided to the learner in order of increasing complexity

- Graphic rather than textual comparisons are shown between learner results and expert results 
- A limited number of stock feedback messages present color-coded graphic and text form during model building

- Canned author-written reflections are provided following learner reflection

- Unnecessary natural language generation tools are avoided

- Direct rather than Socratic instructional strategy is used

Constraints placed on two-way learner-to-simulation message communication, mostly through symbols, avoids costly interpretation processes that can be easily misunderstood. The net result of the Dragoon messaging discipline is reduced confusion from misinterpretation, and economy of conversational interactions that over time, through repetition, becomes a pattern for thinking and problem solving.

\subsection{Conclusion}

The message construct has been a basic concern of the intelligent tutoring community from the beginning, without being addressed directly as a topic in its own right. The earliest ITS experiment, SCHOLAR, tested the use of static message structures that could be populated from a data base, with relatively little emphasis on higher-level strategic issues.

Once adaptation by a conversational engine had been demonstrated, research questions tended to be influenced by theories of learning, instructional philosophy, or general strategic concepts, rather than attention to the messaging system. Yet proof-of-concept systems testing the limits of sophisticated strategies implementation began to borrow message-related terms from existing instructional design literature and practice. From programmed instruction came references to 
"prompt", "hint", and "feedback"; from cognitive psychology came terms like "scaffold", "model", and "schema".

Despite the fact that it is not often targeted or studied as a topic in the ITS literature, virtually every ITS system had to define specialized structures to carry out the unavoidable function of messaging. Fox (1993) observed of tutorial designers that they “...have typically had little research on which to base their design decisions and have perforce designed systems with unexplored assumptions regarding the nature of such interaction informing the design" (p. xii). She further observed that

\begin{abstract}
...Although all tutoring systems have implicit theory or theories of minute-level interaction built into them, little research has been done to form an empirical foundation for such theories, and hence current systems tend to be based on the designer's intuitions rather than on data. (p. xi)
\end{abstract}

More recent work on simulation environments has forced questions of strategy, conversation structure, controls for learner responding, messaging, and representation as separate design problems into the spotlight. The value of attending to design details at the conversational level of interaction and the value of a disciplined messaging system in interactive designs is illustrated in: Johnson et al's work on STEVE with their studies of non-verbal cues like gestures and body language; Hollan et al's work on STEAMER; Forbus' work on the Feedback MiniLab; and vanLehn's work on Dragoon. The message construct has been an unrecognized key factor in these advanced designs. Dragoon, especially, illustrates that simplicity and economy can be 
achieved in such conversational designs. Examining these systems has led us to expand our notion of instruction as conversation and of the key role of the message construct in designing conversations more interesting than most of us probably anticipated.

\section{References}

Anderson, J. R. (1976). Language, memory, and thought. Hillsdale, NJ: Erlbaum Associates.

Anderson, J. R. (1996). ACT: A simple theory of complex cognition. American Psychologist, 51(4), 355.

Anderson, J. R., Boyle, C. F. \& Yost, G. (1985). The geometry tutor. Proceedings of the 1985 International Joint Conference on Artificial Intelligence. Los Angeles, CA:IJCAI, 1-7.

Anderson, J. R., Corbett, A. T., Koedinger, K. R. \& Pelletier, R. (1996). Cognitive tutors: Lessons learned. Journal of the learning sciences, 4(2), 167-207.

Burton, R. \& Brown, J. S. (1979). An investigation of computer coaching for informal learning activities. International journal of man-machine studies, 11, 5-24.

Carbonell, J. R. (1970). AI in CAI: An artificial intelligence approach to computer-assisted instruction. IEEE transactions in man-machine systems, 11(4), 190-202. 
Chi, M. T. H., Siler, S. A., Heisawn, J., Yamauchi, T and Hausmann, R. G. (2001). Learning from human tutoring. Cognitive science, 25: 471-533.

Cole, M. (1971). The Cultural Context of Learning and Thinking. Basic Books; New York.

Collins, A. L. (1986). A sample dialogue based on a theory of inquiry teaching. Technical Report 367. Cambridge, MA: Bolt Beranek and Newman.

Collins, A. L. (1976). Processes in acquiring knowledge. In R. C. Anderson, R. J. Spiro and W. E. Montague (Eds.), Schooling and the acquisition of knowledge. Hillsdale, NJ: Erlbaum. Also, Technical Report BBN-3231. Cambridge, MA: Bolt Beranek \& Newman. DTIC AD020270. Available at: http://www.dtic.mil/dtic/tr/fulltext/u2/a020270.pdf .

Collins, A. L. (1977). The goal structure of a Socratic tutor. Proceedings of the 1977 annual conference of the Association for Computing Machinery. New York: Association for Computing Machinery, 256-263. Also, Technical Report BBN-3518. Cambridge, MA: Bolt Beranek \& Newman. DTIC AD038359. Available at: http://www.dtic.mil/dtic/tr/fulltext/u2/a038359.pdf .

Collins, A., \& Stevens, A. L. (1982). Goals and strategies of inquiry teachers. In R. Glaser (Ed.), Advances in instructional psychology (Vol. 2). Hillsdale, NJ: Erlbaum 
D’Mello, S., Olney, A \& Person, N. (2010). Mining collaborative patterns in tutorial dialogues. Journal of educational data mining, 2(1), 1-37.

Forbus, K., Ferguson, R., Hyun, S., \& Everett, J. (1993). Qualitative Reasoning about Function: A progress report. In Working Notes of Reasoning About Function Workshop. Palo Alto, CA: Association for the Advancement of Artificial Intelligence, 31-36.

Fox, B. A. (1993). The human tutorial dialogue project: Issues in the design of instructional systems. Hillsdale, NJ: Lawrence Erlbaum Associates.

Graesser, A. C., Person, N. \& Huber, J. (1992). Mechanisms that generate questions. In T. W. Lauer, E. Peacock and A. C. Graesser (Eds.), Questions and information systems. Hilldale, NJ: Lawrence Erlbaum Associates.

Hollan, J. D., Hutchins, E. L. \& Weitzman, L. (1984). STEAMER: An interactive inspectable simulation-based training system. AI Magazine, 5(2), 15-27.

Johnson, W. L. \& Lester, J.C. (2016). Face-to-face interaction with pedagogical agents, Twenty years later. International journal of artificial intelligence in education, 26:25-36.

Johnson, W. L. \& Rickel, J. (1998). Steve: An animated pedagogical agent for procedural training in virtual environments. SIGART Bulletin, 8, 16-21. 
Johnson, W. L., Rickel, J. W. \& Lester, J. C. (2000). Animated pedagogical agents: Face-to-face interaction in interactive learning environments. Journal of artificial intelligence in education, 11, 47-78.

Johnson, W. L. \& Lester, J. C. (2016). Face-to-face interaction with pedagogical agents, twenty years later. International journal of artificial intelligence in education.26:25-36.

Merrill, D. C., Reiser, B. J., Ranney, M. \& Trafton, J. G. (1992). Effective tutoring techniques: A comparison of human tutors and intelligent tutoring systems. The journal of the learning sciences, 2(3), 277-305.

Pea, R. D. (2004). The social and technological dimensions of scaffolding and related theoretical concepts for learning, education, and human activity. Journal of the learning sciences, $13(3), 423-451$.

Quintana, C., Reiser, B. J., Davis, E. A., Krajcik, J., Fretz, E., Duncan, R. G., Kyza, E., Edelson, D. \& Soloway, E. (2004). A scaffolding design framework for software to support science inquiry. Journal of the learning sciences, 13(3), 337-386.

Rickel, J., \& Johnson, W. L. (1999). Animated agents for procedural training in virtual reality: Perception, cognition, and motor control. Applied artificial intelligence, 13:343-382. 
Shute, V. \& Glaser, R (1990). A large-scale evaluation of an intelligent discovery world: Smithtown. Interactive learning environments, 1(1), 51-77.

Suppes, P. (1969). Computing technology and the future of education. In R. C. Atkinson and H. A. Wilson (Eds.), Computer-assisted instruction: A book of readings. New York: Academic Press, 41-48.

vanLehn, K. (2006). The behavior of tutoring systems. International journal of artificial intelligence in education, 16(3), 227-265.

vanLehn, K., Wetzel, J., Grover, S., \& van De Sande, B. (2016). Learning how to construct models of dynamic systems: an initial evaluation of the dragoon intelligent tutoring system. IEEE Transactions on Learning Technologies, 10(2), 154-167.

Wenger, E. (1987). Artificial intelligence and tutoring systems. Los Altos, CA: Morgan Kaufmann.

White, B. Y. \& Frederiksen, J. R. (1990). Causal model progressions as a foundation for intelligent learning environments. Artificial intelligence, 42(1), 99-157.

Wood, D., Bruner, J. S. \& Ross, G. (1976). The role of tutoring in problem solving. Journal of child psychology and psychiatrics, 17:89-100. 
Woolf, B. \& McDonald, D. D. (1984). Building a computer: Design issues. IEEE Computer, 17(9), 61-73. EJ320161 


\section{Chapter 5 \\ Message Design, the Learning Sciences, and Social Learning Theory}

\subsection{Designing Conversations: What is Designed?}

Designing conversations is only possible in an indirect sense; even though conversational forms of instruction are desirable, designers can’t actually design them. Designers can design:

- Occasions for conversations

- Circumstances and environments around conversations

- Rules or guidelines for the conduct of conversations

- Contexts of action leading up to conversations

- Scaffolding rules to guide and discipline conversational exchanges

- Topics for conversations

- Objects to converse about

- Tasks during which conversations can occur

- Questions that lead to conversations

- Conversational contingencies

- Engines that enact conversations

The intelligent conversational systems reviewed near the end of Chapter 4 were simulations, which can be interesting and powerful sources of conversations. Three of the examplesSTEVE, Feedback MiniLab, and Dragoon - rely heavily on student initiative and active interaction with computer models, coupled with messaging systems. All of these represent excellent application of messaging to achieve conversational instruction, but they represent, in 
general, a high-end, expensive approach. In this brief chapter, we review three approachesCSILE, Problem-based Learning, and Reciprocal Teaching — that are low-end technologically and more readily applied by instructors in classrooms. Only one of these relies on hardware and software technology as a vehicle for holding learner-to-learner conversations, and even that system can be used without the technology.

All of these examples rely on human social intelligence; all have proven effective in everyday application; and, most important to our purpose, all rely directly on the message construct as a central architectural element. Their strategic focus is on social interaction using disciplined message typologies and together they provide a clear case study of how conversation design involves the design of occasions, circumstances, environments, rules, guidelines, context of actions, scaffolding rules, topics, objects, tasks, and questions that lead to conversations.

\subsection{Message Typing in Computer Supported Intentional Learning Environments (CSILE)} According to Scardamalia and Bereiter, the strategic concept of an intentional learning environment is "to create a classroom activity structure in which active knowledge-building is the natural adaptive thing to do" (Bereiter \& Scardamalia, 1993, p. 212).

Experimental versions of the knowledge-building community approach vary considerably in amount of structure and teacher direction but they are all committed to moving toward a self-maintaining knowledge-building community in the classroom. (p. 214-5) 
Based on the idea of "progressive problem solving in the construction of knowledge" (p. 214), the CSILE concept is also firmly rooted in the concept of a message ontology: a typology of messages used strategically as a tool to create instructional conversations among learners.

CSILE (Computer-Supported Intentional Learning Environment), marketed today in the form of Knowledge Forum ${ }^{\circledR}$ software, embodies a theory of intentional learning proposed by Bereiter and Scardamalia (Bereiter \& Scardamalia, 1989; Scardamalia, et al, 1987; Scardamalia, 2004). The intentional learning theory holds that learners should be led to take an active part in planful efforts toward learning and the creation of new knowledge. Learners, in this view, should take part in environments where they realize that learning through active participation is intentional on their part.

The CSILE learning environment places groups of learners with a common workspace for the purpose of collaborative learning for the joint creation of knowledge. The method of interaction within the CSILE workspace is conversational and involves learners making contributions into the workspace using a limited but strategic set of message types, which are referred to as "scaffolds". The key strategic structure in CSILE is the selection of the set of scaffolds that learners can contribute into the workspace. In this system, it is the learner, not the instructor, that creates the messages.

There are three different standard sets of scaffolds that can be used in the CSILE workspace. One set is focused on joint theory building, a second on joint experimentation, and a third on the expression and discussion of opinions. Instructor-designers may choose a standard set of 
scaffolds to use or may define custom sets. In this sense, the instructor also becomes an instructional designer in the more formal sense of the term: by designing instruction through a means one step removed from direct, didactic teaching.

A learner participates in the CSILE workspace by adding a scaffold, a note whose type must be chosen from among the deliberately-limited set of scaffolds the instructor-designer has chosen. For example, if the instructor-designer has chosen to use the joint theory building scaffold set, contributions learners may make to the workspace include only "My theory", "I need to understand", "New information", "This theory cannot explain", "A better theory would be”, and "Putting your knowledge together". A learner may contribute scaffold-messages of any of these types and only one of the types. One learner may state a theory in a note about the problem at hand. Another learner might respond to that theory by asking for a further explanation, or by showing how the theory lacks explanatory capability. An alternative theory may be proposed by a third learner.

The experimenting scaffold set contains scaffold types: "My goal", "Information", "My prediction is", "The result is", and "I learned that". A third scaffold set for the expression and discussion of opinions contains "Opinion", "Different opinion", "Reason", "Elaboration", "Evidence", "Example", and "Conclusion" scaffold types. These standard sets of scaffold are logically organized in commonsense patterns that constitute conversational forms the instructordesigner wants learners to learn to engage with in a natural and familiar manner. Through multiple exchanges in a conversation among themselves, a group of learners uses the scaffolds afforded to produce a body of shared knowledge. 
In theory, rigorous identification of scaffolds by type encourages patterns of thinking aligned with the logic of knowledge-seeking conversation, so the types chosen must be carefully weighed. The construction and use of a scaffold-message ontology in CSILE brings the instructional designer face-to-face with the issues of designing at the message layer. Scaffolds are message types, and instructors can engage in message system design experimentally. CSILE also opens the question, "Could learners experiment with choosing their own scaffold types and deliberately experiment with self-direction of their own knowledge creation process?"

As learners participate, they experience the creation of knowledge within the group. The knowledge may not reach the Einstein level, but learners may possibly have an experience of the great satisfaction of having created what to them was new knowledge and having engaged in an Einstein-like kind of thinking. CSILE as an instructional approach can also be adapted by an imaginative instructor in a technology-free environment. Media as simple as a bulletin board and $3 \times 5$ cards labelled with message (scaffold) types would serve.

\subsection{Problem-based Learning (PBL): Disciplined Conversations for Problem Solving}

Problem-based learning as described by Barrows (Barrows \& Tamblyn, 1980; Barrows, 1986, 1992, 1996) also relies on selected types of learner contributions — messages — in a disciplined conversation that simultaneously establishes subject-matter and builds metacognitive skill. Problem-based learning, according to Barrows, takes place in a small-group setting. Group sessions are monitored by a tutor whose function is to help the group discipline its knowledge- 
seeking activities. Problem-based learning has been widely imitated, but modifications to Barrows' procedure often return poor results (see McDonald \& Gibbons, 2009). The account here describes Barrows' original model and the record-keeping process that uses message categories to solve medical cases, while at the same time instilling in group members knowledge about the problem-solving process as well.

Each member of a problem-solving group is assigned a question and is responsible for tracking and annotating answers to that question for the group, thus creating simultaneously a record of, and agenda for, the group's problem-solving activities. Patterns of assigning questions to group members vary, but a common pattern is to assign one group member to keep a record of "What do we know?", and another to keep a record of "What do we need to know?" A third member might be assigned to record information sources the group has planned to consult during the next break in group activity; a fourth member might then keep a list of action item assignments detailing the information-seeking tasks assigned to group members.

The action of problem-solving groups proceeds without direct instruction. In medical education, where PBL originated, the group works toward its own solution of a case, which is presented to them by a tutor using information from a case book that contains data about the patient, the complaint, and a history of test results. The tutor's role is to supply case information to the group as they ask for it, to help the group to stay on course, and to help them self-evaluate their progress and problem-solving processes. The group asks for information items as they feel they need them, but the tutor may resist by inquiring about the reasoning behind the request. According to Barrows: 
Attempts to define this teaching role usually concentrate on what the tutor should not do. He is told that he should not put students into a passive learning role by giving them facts they need or by lecturing them; students should actively acquire facts they need on their own. The tutor is also told that he should not tell his students whether their ideas presented in discussions or their answers to questions are right or wrong; they should find out for themselves, under the tutor's guidance. (Barrows, 1992, p. ii)

Barrows' problem-based learning involves message layer design in two ways: (1) requiring that records be kept by the group members in answer to their respective questions, and (2) requiring that the group ask for specific items of information about the case. The group is forced to define what messages it needs to seek, and the group's requests lead to specific information of specific types being provided. In CSILE, the effect of the question categories is to focus the informationseeking conversations of the group, but also to help the group become aware of the structure of information required for solving their problem. Over the course of multiple problems, the group becomes expert in seeking specific types of information-specific types of messages. Without realizing it at first, the group becomes expert in message-seeking.

\subsection{Reciprocal Teaching and the Management of Messages}

Reciprocal teaching (Brown \& Palincsar, 1989; Rosenshine \& Meister, 1994) is a group instructional method in which critical processes of meaning-making, problem solving, and skillbuilding occur through discussions among group members. As with PBL, there have been many 
variations on the method described. Here we will adhere to the original Brown and Palincsar variation.

Reciprocal teaching uses group conversations to create a visible, publicly-observable model of invisible, internal cognitive processes. Prior to a group conversation, group members are taught a questioning process and a set of questions that constitute the core of cognitive processes being learned. For example, if the immediate target activity of the group is to learn to comprehend written texts, the core model consists of asking the kind of critical analysis questions that would lead to an understanding of the text. Group members take turns participating in the conversation of the group, asking specific, assigned questions when they see the moment is right for that question. Through repeated participation in this externalized problem-solving process, learners appropriate group processes into their individual processes. The reciprocal teaching process is portable, being content-independent, and has been used to teach many subject-matters. Learners are exposed to specific subject-matters, but more importantly they learn the critical thinking and knowledge production skills of a particular knowledge domain as well.

The relevance of reciprocal teaching to our discussion of the message construct is that by determining the questions asked, the group leader defines a model of the thinking process to be learned, and that model is expressed in terms of a particular structuring of questions (which are messages) that draw forth answers through discussion (also in the form of messages). The effect is to make manifest an otherwise invisible model of cognitive processes to the group's view. Multiple experiences of this model enactment process allow learners to assimilate and adopt the process of questioning and seeking answers in the form of messages. 


\section{Conclusion}

The systems we have reviewed here have much in common: they are all adaptable to a variety of subject-matters; they all instruct metacognitive skills through performance modelling; and they are all capable of transferring responsibility for enacting instruction from technology to the learner, since even the CSILE effects can be produced off-line as well as online. Most relevant to our hypothesis, all of the examples in this chapter are based on a system of messaging ontology that clearly highlights the message construct as a source of real design value. Specifically, manipulation of the invisible message element, rather than complex technological machinery, seems to account for much of the effectiveness of these examples.

This is not a dismissal of the machine or of technology-based design, which was shown in Chapter 4 to be capable of facilitating highly efficient symbolic interaction and tutoring during imaginative construction activities in a way that would be impractical in most human tutoring settings. However, we note in Skinner's finding, described in chapter 3, that it was the structure of the programmed frame and its message content, not the teaching machine, that accounted for most of the difference provided by the instructional experience. Moreover, once the program was freed from the machine, it could be expressed in a greater variety of interesting forms. We speculate that similar advances might be discovered if increased attention were to be paid to the message construct and its configurations in designs. 


\section{References}

Barrows, H. S \& Tamblyn, R. (1980). Problem-based learning: An approach to medical learning. New York: Springer.

Barrows, H. S. (1986). A taxonomy of problem-based learning methods. Medical education, 20, 481-486.

Barrows, H. S. (1992). The tutorial process. Carbondale, IL: Southern Illinois University Press.

Barrows, H. S. (1996). Problem-based learning in medicine and beyond. New directions for teaching and learning, 68, 3-12.

Bereiter, C. \& Scardamalia, M. (1989). Intentional learning as a goal of instruction. In L. Resnick (Ed.), Knowing, learning and instruction: Essays in honor of Robert Glaser. Hillsdale, NJ: Lawrence Erlbaum Associates, 361-392.

Bereiter, C. \& Scardamalia, M. (1993). Surpassing ourselves: An inquiry into the nature and implications of expertise. Chicago, IL: Open Court.

Brown, A. L. \& Palincsar, A. S. (1989). Guided, cooperative learning and individual knowledge acquisition. In L. B. Resnick (Ed.), Knowing, learning, and instruction: Essays in honor of Robert Glaser. Hillsdale, NJ: Lawrence Erlbaum Associates. 
McDonald, J. \& Gibbons, A. S. (2009). Technology I, II, and III: Criteria for understanding and improving the practice of instructional technology. Educational Technology Research and Development, 57(3), 377-392.

Rosenshine, B. \& Meister, C. (1994). Reciprocal teaching: A review of the research. Review of educational research, 64(4), 479-530.

Scardamalia, M. (2004). CSILE/Knowledge Forum ${ }^{\circledR}$. In Education and technology: An encyclopedia. Santa Barbara: ABC-CLIO, 183-192.

Scardamalia, M., Bereiter, C., McLean, R. S., Swallow, J. \& Woodruff, E. (1987). Computer supported intentional learning environments. In A. Collins (Chair), Strategies for teaching thinking skills with interactive technologies. Symposium conducted at the meeting of the American Educational Research Association, Washington, DC. (ED 288913) Downloaded from: https://files.eric.ed.gov/fulltext/ED288913.pdf . 


\section{Chapter 6 \\ Results and Conclusion}

\subsection{Reviewing Our Claim and Our Case}

In this monograph we have examined evidence for the existence of an instructional design construct, the message. We have provided several historical cases that show that the message construct has been used by instructional designers for over seventy years, although due to shifting fashions in technology and learning theory it has not been specifically identified. We argue that the message is the primary building block within one of seven functional layers of an instructional design. Functional layers are key elements of the architectural theory of instructional design: an approach that focuses the attention of the designer on a basic set of functions performed by virtually all instructional artifacts (Gibbons, 2014).

The architectural theory of instructional design, encompassing the message construct and the message design layer, are products of a recent increase in emphasis on design for instructional purposes (Rowland, 1993; Hokanson \& Miller, 2009; Smith \& Boling, 2009; Clinton \& Hokanson, 2012; Gibbons, 2014; Ertmer et al, 2017). They are products also of an increase in emphasis on functional design among major design fields external to instructional design (Schon, 1987; Brand, 1994; Fowler \& Beck, 1999; Baldwin \& Clark, 2000; Hartson, 2003; Kitamura et al, 2004). The construct, the layer, and the theory must be understood within the broader context of the new approach to designing that they represent. All are considered in the following discussion. 


\subsection{Selection of Cases}

The spectrum of examples reviewed in this volume was intended to demonstrate the consistent, if tacit, appropriation of the message construct across contexts and time. The cases appearing here were selected: (a) because they represent a seventy-year historical perspective of instructional designing, and (b) because they differ in as many dimensions as possible. We have presented cases from programmed instruction; from CSILE used to create group knowledge; from the TICCIT keyboard offering structured learner control; from team-based medical diagnosis; from procedural instruction provided by a robot; and from a robot evoking emotional responses. We aimed as well to avoid the bias of a specific learning theory, technology, community of designers, or instructional venue.

\subsection{The Message Layer and the Architectural Theory}

In order to make a convincing argument for the message layer, we must explain its relationship with the other layers described in the architectural theory. Our discussion and conclusions presented in this chapter, therefore, position the message layer within the network of other layers. Layers interact with each other during both design and delivery of instruction (though in different ways during each), particularly in forms of instruction that are in any way adaptive. Therefore the full architectural theory is addressed in this chapter because coherence among layers, and yet the clear delineation of their functions and the design tensions they impose on one another, must be considered in the discussion of any single layer. 


\subsection{Detecting the "Hidden" Message Construct}

We have worked in the spirit of Clark's "active ingredient" process (Clark, 2009) to bring the message construct into clear relief. Clark proposes a 4-stage process that "emphasizes the identification and application of the 'active ingredients' of effective instructional methods and a strategy for translating active ingredients into the most effective instructional technologies...."

(p. 4). Our research corresponds roughly with the description of Clark's stages one and two, with the same purpose, which is to identify a new, testable construct.

Stage one of Clark's process is descriptive: "new constructs are described, defined, measured, and sometimes hypotheses are generated" (p. 7-8). This involves "descriptive research that is most often the beginning of new research initiatives and new technologies" (p. 8). In the second stage, "hypotheses are linked to theories and the theories are tested and revised based on data from controlled laboratory and field studies" (p. 8), leading to "new insights about complex events" (p. 9). We have used an architectural theory of instructional design as our starting point, and the literature we have surveyed consists of numerous historical applications, from which we have sampled a set that varied along the widest range of dimensions, theories, venues, and design circumstances, in order to avoid theory bias.

The active ingredients we need as the core of a new technology are the causal agents.... We have evidence that these ingredients influence the problem we want to solve at the deepest structural level and so they must be centerpieces in a solution. (Clark, 2009, p. 14) 
What we have seen is that across three major shifts in dominant psychological and learning theories (behaviorist, cognitive, and social-learning), the message construct persisted, hidden, as it were, in plain sight. It has masqueraded as: frame content in an instructional program; a bit of display content in a structured taxonomy; a type of classroom utterance; or a stimulus question in a group learning session. The typologies produced in all three periods that we have studied are signposts, pointing to these theorists' drive to understand the nature of instructional communication more deeply. Within each epoch the search was clearly to define the primary constituents of instructional conversations for which there could be no smaller, well-defined parts. Theorists and designers alike can be viewed as probing for a solid bottom, hoping to find a foundation that would not vanish as they reached it.

\subsection{The Message Layer: A Ubiquitous Swiss Army Knife}

Once we look, the message construct appears everywhere; it is ubiquitous. We can discern it clearly in works governed by different learning-theoretical positions (behaviorist, cognitivist, constructivist, constructionist, and social learning); it appears in all major instructional venues (classroom, tutorial, Intelligent Tutoring Systems, conventional media products); and it is useful to virtually all designer roles (teacher-designer, student designer, commercial designer, research designer). Messages can be created by a designer, by learners (as in CSILE and reciprocal teaching), or by teams (as in problem-based learning). Some uses of message, as in TICCIT and the examples reviewed from social learning theory, require learner participation. And in instructional settings that involve conversational interaction, using messages is the key to implementing a strategic plan. In designs that blend media forms and usage formats, messages conveyed by different media objects must be deliberately coordinated across individual products. 
The message layer can function as a unifying structure facilitating coherence among different media forms and event sequences.

The message construct is also in many ways like a designer's swiss army knife, playing a role in strategic functions at multiple levels. Because messages are abstract and pre-representational, they can convey many kinds of meaning. Besides specifying explanations or declarative information to be communicated, messages also support the expression of instructional qualities often overlooked in designs: feelings, emotions, personality, and presence.

\subsection{The Message Layer and the Order of Design}

The architectural theory proposes that the order of the design process emerges naturally from the requirements, priorities, and constraints presented by specific design problems, and in turn, the problems specific to designing within each of the layers specified by the theory. Within this general ordering scheme, the message layer receives, as a starting point, structures from an evolving strategic plan. The message layer design processes deconstruct high-level blocks of strategic intent into lower-level, atomistic units of message. Once this is done, messages can be matched with conversational patterns and tangible media forms and specific expressions by the design processes of the representation layer.

The ordering of the actual design process is, therefore, not absolute; it is relative to the specific design problem. For example, instruction on proper hygienic measures to be taken by medical workers may be required to include a specific, pre-defined set of messages that must be conveyed; in this case, the message layer can predominate and constrain the designs of other 
layers. Any layer can take precedence in this way, depending on the constraints of the design problem.

\subsection{The Independent Design of the Message Layer}

Architectural design theory proposes that layer designs may be pursued semi-independently, but that they also require frequent integration and reconciliation with other layers. The claim for the independence of message layer design is supported by three arguments discussed at length in the sections that follow.

\subsubsection{The enhanced impact and nuance attainable through independent message design}

The first argument for considering the message layer as an independent design problem is the increased precision of effect and the greater affective nuance attainable through skillful message design.

If the message construct is valid as we maintain, the independent design of instructional messages has immense impact in the hands of one trained in its techniques and principles. A message design is: (a) the most complete expression of the nuanced intentions of an instructional strategy, (b) the point where the designer is encouraged to implement more interactive and conversational instructional approaches, (c) the point where a designer can influence the focus of conversational exchanges, even among students engaged in cooperative learning, and (d) the point where the designer is able to capture and weave into the design emotive and value messages that would otherwise be omitted. 
No defined discipline of message design exists within the instructional technology field. Other experience design fields (e.g., film, drama, writing) do support message design specialties and have an abundance of practical literature and an sub-industry of training programs. ${ }^{1}$ Film designers use message design techniques such as storyboarding and team reviews in the creation of artifacts, teaming writers with concept artists to evolve sophisticated message designs that have both intellectual and emotional impact. A sub-specialty of this field of practice includes the designers of highly persuasive advertising. What if this level of skill was applied to the design of efficient instructional messages by design team members who considered their main concern instructional message design? In the absence of this skill, talented writers and editors are often hired from other fields to work in ID, often, unfortunately, without becoming part of the instructional technology field and sharing their craft because they do not find their specialty represented there in a substantial way.

If message layer design were recognized as a valid ID process, it would reveal a skill gap in the traditional composition of design teams. Message layer design is interposed between the formation of a high-level instructional strategy and its expression in the form of detailed representations. It is the point in design where the members of the team should pause to give

\footnotetext{
${ }^{1}$ Most people are unaware that one of the primary motives for the organization of the Academy of Motion Picture Arts and Sciences (today, sponsor of the Academy Awards) was to train and produce training materials for the displaced workers in a motion picture industry that had been turned on its head by the sudden introduction of talking pictures. (Gomery, 2005, p102-3) 
thoughtful consideration to mapping the details and intentions of a decomposed strategy with the details of media resources that enact that strategy.

It is uncommon, however, to observe this pause in the practices of the average design team, because it is a difficult for a team to jump from the relative comfort of a concrete strategy plan to the generation of an abstract plan for message structures. In the first place, it is difficult to envision things in the abstract, but this jump is further complicated by the simultaneous need to plan the merger of abstract content elements, strategy elements, and message elements together into a master plan. The content, often being new and foreign to the designer, complicates things more, so it is natural for a design team working under time pressures to reach for a concrete closure as quickly as possible, ignoring questions about abstract message plans. What's more, it is unlikely that during training anyone mentioned to the team members the idea of message design as a strategic advantage.

Representation and strategy layer designs have become more specialized and familiar in common design practice over time because they are relatively concrete and have been recognized for decades in the literature as critical areas of design focus. Message design and student response (control) system design (Gibbons \& Langton, 2016) are new and unexplored areas because they are much less concrete and are difficult to imagine. They are also little addressed in the literature of the instructional technology field.

Message and control system design require the designer to think in abstract structural terms about interactions. The details of these designs exist together at the very crux-point of the 
interactions that designers envision. Without messages and their eventual representation, there would be nothing for the student to respond to; without a system of controls there would be no way for the student to respond to messages as represented. Message and control system design considerations are and always have been essential to interaction design, and interaction at some level is a feature of the vast majority of designs. This suggests that there has always been at least tacit recognition of these layers in the minds of designers all along. What is needed is for these unrecognized elements of a design to emerge in their own right as topics, so that they can become centers for more extensive research and development and become "visible" to the practicing designer.

\subsubsection{The need for adaptivity and generativity.}

A second argument for considering message layer as an independent design problem is that it advances the formal basis for designing adaptive and generative instructional forms beyond the current general practice. Adaptivity and generativity are closely related. Adaptive instruction adjusts itself to the immediate needs of the learner as these are discovered from learner responses. Adaptivity requires that some portion of instructional interaction and sequencing be generated at the time of instruction. Live instruction and tutoring are the gold standard for adaptivity and generativity. Training for live tutors and classroom teachers includes among other things the study of how to form and then represent an appropriate sequence of messages within a conversation. Numerous studies of human tutoring techniques (Collins et al, 1974; Merrill et al, 1992; Fox, 1993; Graesser et al, 1995; Heffernan \& Koedinger, 2002; D’Mello et al, 2010); VanLehn, 2011) have informed the design of intelligent tutoring systems (Collins, 1976; 
Graesser, 1999), leading to the creation of sophisticated systems that approximate instructional conversations (D’Mello \& Graesser, 2013).

Adaptivity and generativity are not possible without considering the message as a basic structural element to be designed and sequenced. A tutor may express utterances in media form (speech, text, sketch, etc.), but prior to making external representations there must exist an abstract precursor of message intention in the mind of the tutor that can be given concrete form and then expressed. Intention precedes expression.

The field of intelligent tutoring is built on the quest for adaptive and generative instruction. Its development over time illuminates how central both properties are to instructional conversations. In ITS research, exploring mechanisms for generativity has been primary. Principles for message design have been secondary, except in systems like MiniLab from STEAMER and the STEVE boiler room simulation. These systems were designed to explore the effective use of conversational forms.

A primary obstacle for ITS designers has been the complexity and cost of software to achieve even minimal levels of adaptivity — the challenge of knowing what to say and when to say it. As an alternative to complex analytic and generative systems, Dragoon (VanLehn, 2016) addresses this problem with a less ambitious approach that balances human and machine message generation with a combination of pre-formed messages and human intervention. Baker (2016) describes this approach as "stupid tutoring systems, intelligent humans", stating that in such designs most of the intelligence is in the human rather than the tool. In contrast to traditional ITS 
that depend on sophisticated models of knowledge, student knowledge status, and complicated generative engines, Baker describes a division of labor between ITS and humans in which relatively simple but intelligent software traces problems and offers support for performance as far as the simple program logic allows, after which human tutors provide additional support for messy and nuanced cases. Baker's argument is that sophisticated approaches to ITS design are not scalable, whereas simpler software suites combined with human attention to fewer problem cases may be scalable.

The value of the message construct to this system is that the mechanism of layers can be used to allocate messaging responsibilities across software intelligence and human intelligence. Software logic is assigned a messaging role up to a certain point, while more nuanced message design is provided for certain functions by a less complex but still intelligent tutor.

\subsubsection{The Need to Capture Value Messages in Designs}

A third argument can be made for the independence of the message layer and its treatment as a distinct design problem. This argument holds that during message design a multitude of messages are incorporated into the design that express values the learner may discern either consciously or unconsciously and interpret as a message to or about themselves, or about values in general. Since it is possible for the designer to intentionally influence the most advantageous value interpretations, it makes sense for the designer to be aware of this phenomenon and plan insofar as possible what messages will be projected. During message design this consideration rises to the surface. This is best accomplished deliberately during a message design process, rather than as a by-product of the media production process. 


\subsubsection{Value Messages and Their Importance}

By the use of the term value we mean to invoke a whole constellation of possible between-thelines message interpretations a learner may reach that are signaled by designed features of the instruction. A live instructor or tutor projects a personality, a presence, personal beliefs, attitudes, affinities, social styles, and emotional states. What does it mean when an instructor tells a student "well done" and then frowns and stares at the student? What does it mean when the same instructor smiles? The student says inwardly, "I saw what you said" and gets the message, whichever one it was.

We take it as given that students interpret what they observe and feel, either consciously or unconsciously, and reach conclusions that become an integral part of the broader message of the instruction. Without conscious acknowledgement a learner may ask the question, "Who or what does this instructor think I am?", "What value does this instructor see in me?”, or, "How committed is this instructor to my learning?". The conclusions the learner draws on these and many other points can strongly influence the learner's own levels of commitment, motivation, and engagement. More importantly, it can influence in the long run whether learners perceive themselves as intentional, self-directed, and life-long learners.

After considerable effort, technology researchers have failed to penetrate to the essential principles of an effective live instructor, nor can they produce many of the nuanced favorable learner interpretations and deep personal commitments that the best instructors can inspire. The gulf between live tutor and intelligent tutor becomes clear, sometimes painfully so, in the 
intelligent tutor's inability to represent faithfully the best aspects of personality, style, state of mind, and relatability of the live instructor. Intelligent tutoring is able to handle the intellectual aspects of instruction, but it is not as good at handling affective, or value, aspects that may be more important in the long run.

There is considerable evidence of a strong connection between learning and emotional state. Immordino-Yang and Damasio (2007) assert that, "any competent teacher recognizes that emotions and feelings affect students' performance and learning.... We contend...that the relationship between learning, emotion, and body state runs much deeper than many educators realize and is interwoven with the notion of learning itself" (p.3-4). Citing research on the neurobiological relationship between emotions and learning, they conclude:

As educators have long known, it is simply not enough for students to master knowledge and logical reasoning skills in the transient academic sense. They must be able to choose among and recruit these skills and knowledge usefully outside of the structured context of a school or laboratory. Because these choices are grounded in emotion and emotional thought, the physiology of emotion and its consequent process of feeling have enormous repercussions for the way we learn and for the way we consolidate and access knowledge. (p. 9)

In this view, "emotions are not just messy toddlers in a china shop, running around breaking and obscuring delicate cognitive glassware. Instead, they are more like the shelves underlying the 
glassware; without them, cognition has less support" (Immordino-Yang \& Damasio, 2007, p. 5. See also Immordino-Yang, 2016). Value messages to learners, most often conveyed nonverbally, leave lasting emotional impressions and do influence learning.

\subsubsection{Designing Values into Instruction}

As the field of instructional design continues to mature, we believe that value messages will be increasingly seen as an important class of designed messages because of their emotional and attitudinal impact, and because they are so integrally linked to learning at such a fundamental level. As designers our awareness of value messages will increase as we learn to "see" them, and we will develop better approaches for planning for them, as other design fields have already learned to do. Message layer design provides the most propitious moment for inserting value messages into designs prior to the creation of representations.

An example of how this is done may be seen in the production design process of the motion picture industry. A film's production designer creates what LoBrutto (2002) calls "a cohesive pictorial scheme that directly informs and supports the story and its point of view" (p. 1). The key phrasing here is the reference to the "cohesive...scheme" of the production and the creation of a high-level scheme prior to fleshing out details of a design. In production design, the scheme is abstract and takes form incrementally top-down through the addition of levels of detail to an evolving plan. The abstract production design must take place before the media production of the movie itself begins. LoBrutto describes the work of the production designer in these terms: 
The production designer researches the world in which the film takes place to establish a sense of authenticity. The production designer must interpret and transform the story, characters, and narrative themes into images that encompass architecture, décor, physical space, tonality, and texture.

Production designers use sketches, illustrations, photographs, models, and detailed production storyboards to plan every shot from microscopic to macroscopic detail. Production designers are the heads of the art department and manage a creative team that includes art directors, set decorators, property masters, painters, carpenters, and specialty crafts people. (p. 1)

Production designers create the plan for a motion picture's "world", one that is capable of evoking a series of emotions or an overriding emotional tone. Nothing is left to chance. The look and feel of a production rely on the production designer's larger vision of purpose. It involves judgments on color schemes, compositions, locations, and the action of scenes. The work of a production designer explains the difference between disparate films like Black Panther, Dr. Zhivago, and The Sound of Music. Each film evokes a suite of emotional responses not possible without a unifying theory of the film. Each conveys its planned pattern of messages. The production designer creates the set of non-verbal, nuanced, and unverbalized but salient messages conveyed by a film. The messages evolve from a written script, the vision of a director, and the resources of a producer, but the production designer draws these together and gives them a plan in a coherent design concept before they are committed to media form. 
In the field of document design, Schriver (1997) describes research on the design of anti-drug educational materials, concluding that writers misread audiences and readers misconstrue writers' messages as each tries to identify the values and intentions of the other. Schriver shows that a persuasive document intended to have a real impact on life choices is an invitation to the reader to take part in an "implicit social and rhetorical contract" (p. 188) which promises that the writer is speaking honestly (p. 206). But, as her research showed, the reader turns skeptic, drilling through surface representations trying to detect the motives of the writer, the writer's identity, and the writer's opinion of the reader. According to Schriver, mis-construal on anyone's part can negate the effectiveness of the communication and impair the reputation of the writer and the writer's cause:

Failing to consider the knowledge and values of the real audience can create a lasting negative identity for the organization that may take years to shake. Building a positive identity (and here I am talking about more than just logos, product naming, or graphic style) requires organizations to develop a distinctive voice - through the interplay of text and graphics - that makes evident to audiences that their knowledge and values are understood, respected, and not taken for granted. (p. 204)

Schriver describes how document designers create personas in their own minds that represent the supposed reader — that is, who the writer believes the consumer/reader is. Likewise, Schriver describes how document (or, in terms of our interest here, student) consumers read between the lines to construct the writer's identity. This means that both writers and readers carry on their mental conversations not with the reality of each other but through their imagined conceptions of 
each other. These imaginations are constructed from clues in what the writer writes into the document and what the reader reads into it. She concludes: "Organizations [designers] need to figure out what makes their personality unique and devise an integrated approach that puts that identity in prose and graphics — from planning to production" (p. 206).

While it is difficult to predict the particular mix that may be brought into play for any given document, this study makes clear that readers' constructions of meaning extend well beyond the ideas presented "in the text." Readers' interpretations of documents are shaped by thinking and feeling, by the subtle interplay of cognition and affect. (p. 188189)

We argue that all of the functional layers of an instructional design make contributions to the "personality" posited by Schriver and the film's "world" described above by LoBrutto. We further maintain that message layer design — the planning process — and the subsequent representation layer design - the embodiment process - is the meeting place of all of these contributions, where they are integrated to create the coherent interactive surface of the learner's experience. In this view, if there is an argument to be made for more deeply exploring the principles of message layer design, it is that so many instructional designs begin instead with the surface and fail to consider what lies beneath.

\subsection{Preserving Intent}

The message construct, then, is the focal point for preserving the full spectrum of intentions of the instructional communication. The creative process in instructional design depends heavily on 
the designer deciding what is intended. The more precisely the designer characterizes the intent of the moment, the more precise and adapted to the moment the message can be.

When a student and a tutor enter the flow of synchronized understanding of each other's intentions, their conversation shifts. Participants create a shared context in which words get in the way. What might have been verbalized as sentences becomes telegraphic: "So I should..."; "Exactly..."; “And that means that..."; "Right.". Words may be replaced with gestures, sounds; grunts, wheezes, deep sighs, hasty sketches on paper, or even silence: whatever is most economical for conveying rapidly-multiplying, constantly changing intents.

Austin (1962) would explain that that the communication has become condensed to the barest "performatives" necessary to communicate intent. He states, "for many purposes the outward utterance is a description, true or false, of the occurrence of the inward performance" (p. 8, emphasis in the original). This accords with the definition we are offering of the message construct: that a message is not a representation, but rather an intention to be communica Wenger (1987) deals with this important concept in instructional settings in terms of what he calls epistemic fidelity:

For the purposes of this discussion, let us define a representation of knowledge very broadly as a mapping of knowledge into a physical medium.

It is useful to be able to speak about the knowledge that is the source of this mapping, and we will use the adjective epistemic to refer to this "disembodied" level. Whether such an epistemic level really exists in some Platonic sense is not the point here. The claim is, rather, that the distinction 
between the epistemic and the representation levels is useful in designing and evaluating models of communicable knowledge. (Wenger, 1987, p. 312, emphasis in the original)

The principle that intention precedes expression should lead instructional designers to consider the extent to which they account for, or are even aware of, the full range of their intentions during design. Schriver's description in the previous section of how a reader kens the intentions and person of the writer can be no less true for the student discerning the intentions and the person of the designer. This is a challenging thought that should make designers wonder what the learner "sees". Even more important, it should raise questions whether designers themselves are fully aware of their own intentions as they design. Certainly this is worth exploring individually as well as at the professional level.

\subsection{The Message Layer and Conversation Analysis Structures}

In this section and the section following we make two final points regarding the importance of message layer design, first to emphasize the clear match between message-strategic and conversation-analytic structures, and second to describe how this match-up leads to a natural diagnosis-and-repair mechanism that explains how instructional conversations maintain a productive forward momentum.

Conversation analysis (CA) is a tool for the objective description of structural units of interpersonal exchanges. Its pattern language of conversational regularities describes how a listener can anticipate and interpret the speech actions of another speaker. We propose that the 
lowest-level conversational structures described by $\mathrm{CA}$ relate through a mapping process with low-level goal-defined instructional actions in the form of messages and that higher-level conversational structures of CA correspond with structures an instructional designer can use to structure instructional interactions above the message level. When message-strategic structures correspond with conversational-strategic structures, a path exists by which instructional conversations can be designed.

We have reviewed several examples of message design systems in this monograph that reveal instructional theorists searching for how to map instructional strategy patterns to conversational patterns. It seems clear that these theorists were trying to bridge strategic goals and strategic actions with conversational actions. We believe that the message construct makes possible an explanation of how this mapping can take place.

\subsection{Diagnosis and Repair Involving the Message Construct}

Conversations involve a constant process of repair. Repair is central in the literature of conversation analysis and refers to the act of "interrupting the ongoing course of action to attend to possible trouble in speaking, hearing, or understanding the talk" (Kitzinger,2013, p. 229), with

...Misarticulations, malapropisms, use of a 'wrong' word, unavailability of a word when needed, failure to hear or to be heard, trouble on the part of a recipient in understanding, incorrect understandings by recipients. (Schegloff, 1987, p. 210, as quoted in Kitzinger, 2013, p. 229) 
Repair to a conversational analyst involves one or the other parties to a conversation breaking the rhythm and conversational structure momentarily to: clarify, request repetition, question, reaffirm understanding, or to offer correction, recapitulate, reword, or in some way repair or restore a flow of understanding and synchronization of meaning that has been lost by either of the parties. By this definition, an instructional conversation is a constant process of knowledge repair, whether in the setting of a classroom, a tutoring session, a collaboration of learners, a technology-based interaction, or an intelligent simulation exercise.

Repair is so continuous during the course of live instruction in all of its forms that it is taken for granted. It is only in relation to interaction design — particularly the design of conversational interactions - that it surfaces as a practical concern. That is why the topic of repair became an active center of research as intelligent tutor designers tried to teach computers to detect and remedy the underlying sources of learner errors. By diagnosing the source it was hoped that an appropriate repair could be made.

The concepts of diagnosis and repair are found in the design languages of conversation analysis and instructional design. Tutoring permits close inspection of diagnosis and repair during instruction. Fox (1993) describes tutoring as "collaborative contextualizing of abstract symbols and descriptions" (p. 1). By this she means the process of negotiating shared meanings between conversants (p. 2): "A thoroughly interactive achievement, produced by both tutor and learner" (p. 3). At the point of mis-construal, diagnosis and repair are necessary to restore the forward motion of the conversation. 
Each participant in a conversation attempts to understand what the other knows and doesn't know-their "epistemic status" (Heritage, 2013). In some of the examples we have reviewed in this monograph, the imbalance is understood to exist between one who is more knowledgeable and one less knowledgeable, however, in other examples groups of learners are mutually imbalanced against a problem and are given a set of resources to consult in seeking a solution and in the process achieving a mutual balance for (ideally) all participants.

The complementary concepts of diagnosis and repair were well-known instructional principles long before the advent of technology- and computer-based instruction. Morrison's work on mastery learning (1926) influenced Tyler's implementation of diagnostic and remedial principles (1949). Tyler's student Benjamin Bloom explored mastery and diagnostic testing to become a leading influence in the field of educational technology (Bloom, 1976). The tradition of interest in diagnosis and repair can also be traced backward to the early decades of the $20^{\text {th }}$ century, to the work of Burk, Washburn, and Parkhurst (see Tyler, 1975).

For a long time, the greatest hindrance to the application of diagnosis and repair was the lack of technologies that could lend themselves to adaptive, individualized implementation.

Programmed instruction in its many forms tested adaptive media concepts using existing technologies. With the advent of the computer, a second hindrance to diagnosis and repair became apparent: the lack of theory and practical guidance for the design of conversational styles of instruction. This led to numerous analytical studies of tutor and live instructor practices in their natural settings (Collins et al, 1974; Merrill et al, 1992; Fox, 1993; Graesser et al, 1995; Heffernan \& Koedinger, 2002; D’Mello et al, 2010); VanLehn, 2011). 
The cycle from diagnosis to repair and back again constitutes the central activity of tutorial conversations. Fox (1993, p.53) notes that learners in a tutoring setting often verbalize during problem solving to solicit correction of errors (repair) or to reaffirm their analysis of the problem (diagnosis).

Why do students produce this ongoing commentary? They do it to display to the tutor how they have understood the problem and how they understand what they are currently doing to solve the problem (Fox, 1993, p. 52).

Conversational patterns of diagnosis and repair are everywhere evident in educational technology research and practice: in programmed instruction (Markle, 1964), in cognitive psychology research on bug repair (Brown \& VanLehn, 1980; Koedinger \& Aleven, 2007), in social interaction patterns during group learning (refs), and in studies of interactions during simulation problem solving (Schank, 1994). We propose that the description of the message construct and its relationship to multiple structures of conversation analysis provides new perspective and new tools for research and design on conversational forms of instruction.

\subsection{Conclusion}

The message construct has proven to be quietly durable across time, shifting theories, and changing technologies. We have argued that it corresponds with categories of theoretical conversation structure, and that it supplies tools for the design and study of human-human and human-technology conversational interactions. 
It has been surprising to us to see the extent to which message layer design unites the interests of the classroom instructor, the tutor, the multimedia designer, and the designer of intelligent tutors. This was an unexpected finding that we feel creates a common denominator that unites the research interests of these designers by supplying a new terminological tool. We felt at first that the interests of these different designers would diverge because of their unique media and venue circumstances, but they all appear at some point, either consciously or unconsciously, to subscribe to a stratagem for message design.

We also thought it might be difficult to reconcile differences across learning-theoretic boundaries. We found to the contrary. For example, Hattie and Gann (2011) analyze feedback message properties across three of the same perspectives that we had also chosen; in their terms: objectivism, constructivism, and socio-culturalism. By analyzing feedback messages aimed at four different levels (task level, process level, self-regulation level, and self-level), Hattie and Gann construct a visual organizer as a guide to forming an appropriate dialogic message in the form of a diagnostic question to be asked. Examples of questions they provide include the following: "What happened when you...?", "How does this compare to...?", and "How do you account for...?". The value of Hattie and Gann's work is that it reaches across theoretical boundaries to focus on the selection of appropriate message forms.

This monograph has cut across time and applications in a way that we hope has left the message construct in plain sight. The topic of message seems to us to offer a re-evaluation of past research 
from disparate worlds, looking at formulas, prescriptions, patterns, and techniques from a fresh perspective.

We feel this research report only scratches the surface of an important subject. But it does so sufficiently to focus designer's attention on careful and purposeful design of the message layer prior to media design. Bishop (2014) notes the following regarding message design:

Instructional message design has been described as the 'next step' in the instructional design analytic process - moving beyond deciding what methods are best for bringing about desired changes in student knowledge...toward specifying the exact form an instructional communication system should take for optimal learning.... (p. 374)

We offer here a broader, theory-based, view of the message concept that overcomes a traditional, and excessive, focus on the surface and sensory dimensions of media products. The message construct can help disentangle media research from strategic research by inserting a precursor design construct and process, based on the formation of the message in the abstract, prior to media design. There are many unanswered questions surrounding the creation of adaptive and generative instructional systems that hinge on the divide between message design and representation design. These merit exploration from the perspective of message layer design. 


\section{References}

Austin, J. L. (1962). How to do things with words: The William James Lectures delivered at Harvard University in 1955. Oxford, UK: Clarendon Press. Downloaded 5 February 2020 from: https://pure.mpg.de/rest/items/item_2271128_6/component/file_2271430/content.

Baker, R.S. (2016). Stupid Tutoring Systems, Intelligent Humans. International Journal of Artificial Intelligence in Education, 26, 600-614. https://doi.org/10.1007/s40593-016$\underline{0105-0}$

Baldwin, C. \& Clark, K. (2000). Design rules: The power of modularity. Cambridge, MA: MIT Press.

Bishop, M. J. (2014). Instructional message design: Past, present, and future relevance. In Handbook of research on educational communications technology. New York: Springer, 373-384.

Bloom, Benjamin S. (1976). Human characteristics and school learning. New York: McGrawHill. ISBN 9780070061170.

Brand, S. (1994). How buildings learn: What happens after they're built. New York: Penguin.

Brown, J. S. \& VanLehn, K. (1980). Repair theory: A generative theory of bugs in procedural skills. Cognitive science, 4(4), 379-426. 
Clark, R. E. (2009). Translating research into new instructional technologies for higher education: The active ingredient process. Journal of computing in higher education, 21:418. https://doi.org/10.1007/s12528-009-9013-8

Clinton, G. \& Hokanson (2012). Creativity in the training and practice of instructional designers: The Design/Creativity Loops model. Educational technology research and development, $60,111-130$.

Collins, A. (1976). Processes in acquiring knowledge. Cambridge, MA: Bolt Beranek and Newman, Inc. AD-A020270

Collins, A., Warnock, E. H. \& Passafiume, J. J. (1974). Analysis and synthesis of tutorial dialogues. Cambridge, MA: Bolt Beranek and Newman, Inc. AD776596.

D’Mello, S., \& Graesser, A. (2013). Design of dialog-based intelligent tutoring systems to simulate human-to-human tutoring. In A. Neustein and J. A. Markowitz (Eds.), Where Humans Meet Machines. New York: Springer, (pp. 233-269).

D’Mello, S., Olney, A. \& Peterson, N. (2010). Mining collaborative patterns in tutorial dialogue. Journal of educational data mining, 2(1), 2-37.

Ertmer, P. A., Quinn, J. A. \& Glazewski, K. D. (2017). The ID casebook: Case studies in instructional design, $4^{\text {th }}$ edition. New York: Routledge. 
Fox, B. A. (1993). The human tutorial dialogue project: Issues in the design of instructional systems. Hillsdale, NJ: Lawrence Erlbaum Associates.

Fowler, M., \& Beck, K. (1999). Refactoring: improving the design of existing code. AddisonWesley Professional.

Gibbons, A. S. (2014). An architectural approach to instructional design. New York: Routledge.

Gibbons, A.S. (2014). Eight views of instructional design and what they should mean to instructional designers. In B. Hokanson and A. Gibbons (Eds), Educational communications and technology: Issues and innovations. New York: Springer, 15-36. https://doi.org/10.1007/978-3-319-00927-8_2

Gibbons, A. S. \& Langton, M. B. (2016). The application of layer theory to design: The control layer. Journal of computing in higher education, 28(2), 97-135.

Graesser, A. C., Person, N. K. \& Magliano, J. P. (1995). Collaborative dialogue patterns in naturalistic one-to-one tutoring sessions. Applied Cognitive Psychology, 9, 1-28.

Graesser, A. C., Weimer-Hastings, K, Weimer-Hastings, P. \& Kreuz, R. (1999). AutoTutor: A simulation of a human tutor. Cognitive systems research, 1(1), 35-51. 
Hartson, H. R. (2003). Cognitive, physical, sensory, and functional affordances in interaction design. Behaviour and information technology, 22(5), 315-338.

Hattie, J. \& Gann, M. (2011). Instruction based on feedback. In R. E. Mayer and P. A. Alexander (Eds.), Handbook of research on learning and instruction. New York: Routledge. 249271.

Heffernan, N.T. \& Koedinger, K.R. (2002). An intelligent tutoring system incorporating a model of an experienced human tutor. Proceedings of the 6th International Conference on Intelligent Tutoring Systems, 2363, 596-608.

Heritage, J. (2013). Epistemics in conversation. In J. Sidnell and T. Stivers (Eds.), The handbook of conversation analysis. West Sussex, UK: Wiley-Blackwell, 370-394.

Hokanson, B. \& Miller, C. (2009). Role-based design: A contemporary framework for innovation and creativity in instructional design. Educational technology, 49(2), 21-28.

Immordino-Yang, M. H. (2016). Emotions, learning, and the brain: Exploring the educational implications of affective neuroscience. New York: W. W. Norton.

Immordino-Yang, M. H. \& Damasio, A. (2007). We feel, therefore we learn: The relevance of affective and social neuroscience to education. Mind, brain, and education, 1(1), 3-10. ISBN 978-0-393-70981-0 
Kitamura, Y., Kashiwase, M., Fuse, M. \& Mizoguchi, R. (2004). Deployment of an ontological framework of functional design knowledge. Advanced engineering informatics, 18, 115127.

Koedinger, K. R. \& Aleven, V. (2007). Exploring the assistance dilemma in experiments with cognitive tutors. Educational psychology review, 19, 239-264. DOI 10.1007/s10648-0079049-0

LoBrutto, V. (2002). The filmmaker's guide to production design. New York: Allworth Press. Markle, S. M. (1964). Good frames and bad: A grammar of frame writing. New York: John Wiley \& Sons.

Merrill, D. C., Reiser, B. J., Ranney, M. \& Trafton, J. G. (1992). Effective tutoring techniques: A comparison of human tutors and intelligent tutoring systems. Journal of the learning sciences, 2(3), 277-305. https://doi.org/10.1207/s15327809j1s0203_2

Meyer, J. H. F. \& Land, R. (2006). Overcoming barriers to student understanding: Threshold concepts and troublesome knowledge. New York: Routledge.

Morrison, H. C. (1926). The practice of teaching in the secondary school. Chicago, IL: University of Chicago Press.

Rowland, G. (1995). Designing and instructional design. Educational technology research and development, 41, 79-91. 
Schank, R. C., Fano, A., Bell, B. \& Jona, M. (1994). The design of goal-based scenarios. Journal of the learning sciences, 3(4), 305-345.

Schegloff, E. A. (1992). Repair after next turn: The last structurally provided defense of intersubjectivity in conversation. American journal of sociology, 97(5), 1295-1345. DOI: $10.1086 / 229903$

Schön, D. (1987). Educating the reflective practitioner. San Francisco, CA: Jossey-Bass.

Schriver, K. A. (1997). Dynamics in document design. New York: John Wiley \& Sons.

Sidnell, J. \& Stivers, T. (Eds.) (2013), Handbook of conversation analysis. West Sussex, UK: Wiley-Blackwell.

Smith, K. M. \& Boling, E. (2009). What do we make of design? Design as a concept in educational technology. Educational technology, 59(4), 3-17.

Tyler, R. W. (1949). Basic principles of curriculum and instruction. Chicago, IL: University of Chicago Press.

Tyler, R. W. (1975). Educational benchmarks in retrospect: Educational change since 1915. Viewpoints, 51(2), 11-13. 
VanLehn, K. (2011). The relative effectiveness of human tutoring, intelligent tutoring systems, and other tutoring systems. Educational psychologist, 46(4), 197-221. https://doi.org/10.1080/00461520.2011.611369

VanLehn, K., Wetzel, J., Grover, S., \& Van De Sande, B. (2016). Learning how to construct models of dynamic systems: an initial evaluation of the dragoon intelligent tutoring system. IEEE Transactions on Learning Technologies, 10(2), 154-167.

Wenger, E. (1987). Artificial intelligence and tutoring systems: Computational and cognitive approaches to the communication of knowledge. Los Altos, CA: Morgan Kaufmann. 